\title{
Firminy redibujado: el primer proyecto de la iglesia Saint-Pierre por Le Corbusier ${ }^{1}$
}

\author{
Firminy redrawn: the first project of Saint-Pierre church \\ by Le Corbusier
}

\section{Cómo citar:}

Chaverra, M., Cogollo, M., \& Leserri, M. (2018). Firminy redibujado: el primer proyecto de la iglesia SaintPierre de Firminy-Vert dibujado por Le Corbusier. Designia, 5 (2), 27-65.

${ }^{1}$ El presente artículo hace parte del proyecto de investigación "Conjunto y Arquitectura de Le Corbusier en Firminy-Vert", radicado en el Centro de Investigación para el Desarrollo y la Innovación (CIDI) de la Universidad Pontificia Bolivariana, sede Montería.

*Merwan Chaverra Suárez, Merwan.chaverra@upb.edu.co 0000-0001-7450-3442

Massimo Leserri, massimo.leserri@upb.edu.co 0000-0002-7153-0290

Manuel Cogollo Posada, manuel.cogollop@upb.edu.co 0000-0001-5484-8232
Palabras clave:

Redibujo, iglesia Saint-Pierre de Firminy-Vert, proyecto, Le Corbusier.

Key words:

edraw, Saint-Pierre de Firminy-Vert Church, project, Le Corbusier.

\section{Recibido: 28/03/2018}

Aceptado: 10/06/2018

\section{Resumen:}

La primera versión de la iglesia de Saint-Pierre de Firminy-Vert (Francia), realizada por Le Corbusier y caracterizada por una variedad de elementos arquitectónicos y compositivos que introducen sensaciones apasionantes, proporcionales y perceptibles en el conjunto del proyecto, constituye además un interesante ejercicio de restitución completa y precisa de los dibujos del proyecto. Este artículo presenta resultados investigativos desde una perspectiva analítica, interpretativa y crítica que no pretende abordar una definición de la arquitectura de Le Corbusier, sino la ordenación de documentos y dibujos que reavivan la actividad de aquella propuesta. La metodología usada se sustenta estrictamente en el material documental derivado del proceso y el ejercicio proyectual de la iglesia, lo cual posibilita el entendimiento y la reconstrucción de esa primera versión a partir de las fuentes primarias. 


\begin{abstract}
:
The first version of Saint-Pierre de Firminy-Vert Church by Le Corbusier is characterized by the variety of compositional and architectural elements that introduce exciting, proportional and perceptible sensations into the whole project. It also constitutes an interesting exercise of complete and accurate restoration of the project's drawings. This paper discusses research results from an analytical, interpretative and critical perspective which does not intend to address a definition of Le Corbusier's architecture, but ordering documents and drawings that revive such a proposal. The research methodology is meticulously based in documentary material derived from the church's project process, which enables the understanding and reconstruction of the aforementioned first version from primary sources.
\end{abstract}

\title{
INTRODUCCIÓN
}

El estudio del primer proyecto de la iglesia Saint-Pierre de Firminy-Vert permite comprender mejor este proyecto, como también visualizar la génesis de sus diferentes formas y elementos compositivos. Desde esta perspectiva se han definido cuatro partes que siguen unas pautas consideradas para el análisis.

Inicialmente se examina el programa arquitectónico y su temática litúrgica como paso previo para la realización de los primeros esquemas. Estos se sustentan en elementos preliminares como la memoria arquitectónica del arquitecto, sus intereses plásticos y formales y su sensibilidad por los fenómenos naturales.

A continuación se reconstruyen, en orden cronológico, cada uno de los bocetos y croquis. Estos evidencian las transformaciones generales del primer proyecto y las constantes compositivas, tales como la orientación, la circulación, el soporte y la distribución, las cuales sirven de punto de partida para analizar la representación gráfica. En esta, a su vez, se reconocen los tanteos, las dudas, injerencias y certezas que poco a poco llevaron a materializar y configurar los dibujos iniciales. 
Una vez identificados y analizados los dibujos pertenecientes al primer proyecto, en una tercera sección se realiza una restitución gráfica del proyecto arquitectónico, con el objetivo de ofrecer una visión de este más completa, precisa y en conjunto.

Por último, se presentan las principales consideraciones resultantes del análisis y la descripción del proceso proyectual de la iglesia. Se ponen de manifiesto los elementos que la componen, al igual que la relevancia de los componentes plásticos en la génesis compositiva y de los fenómenos naturales como composición poética.

\section{GÉNESIS DEL PROYECTO}

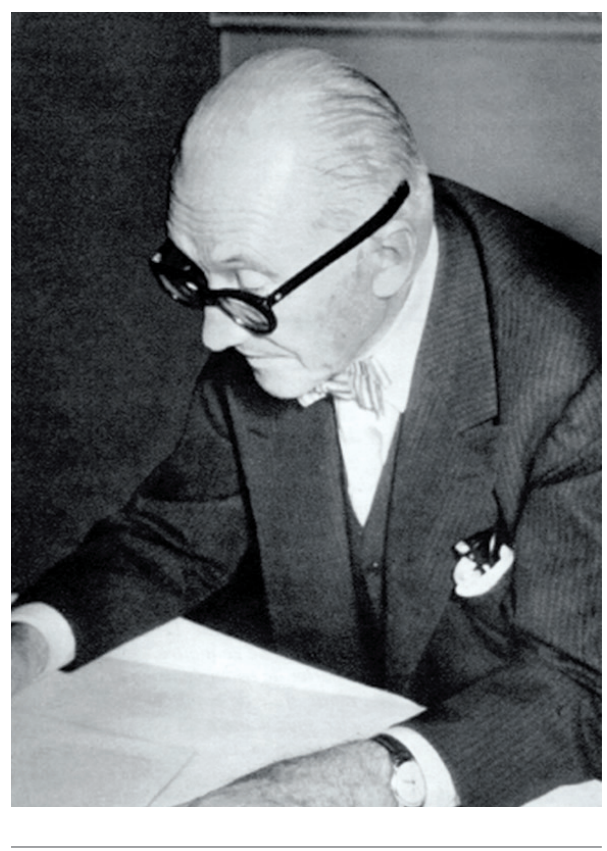

Figura 1. Le Corbusier dibujando la planta de la iglesia Saint-Pierre de Firminy-Vert en 1961. Fuente: Cocagnac (1964, p. 4).

El 10 de junio de 1961, Le Corbusier realizó el primer proyecto de la Iglesia SaintPierre de Firminy-Vert, un hecho paradigmático dentro de la dinámica del Atelier rue de Sèvres en París (Chaverra, 2010). Para la comprensión de esta versión inicial, que significó el origen de todo el proyecto, se analiza a continuación, inicialmente, la composición del programa general. En este sentido se considera, por un lado, dicho programa arquitectónico, es decir, la lista planteada por el cliente en cuanto a necesidades, 
usos y espacios; por otro lado, el conjunto de acciones, fórmulas y objetos orientado a rendir culto público a Dios, esto es, la función litúrgica. Posteriormente, se examina el desarrollo proyectual a través de cada uno de los esquemas y bocetos que dieron origen a esa primera propuesta (figura 2).
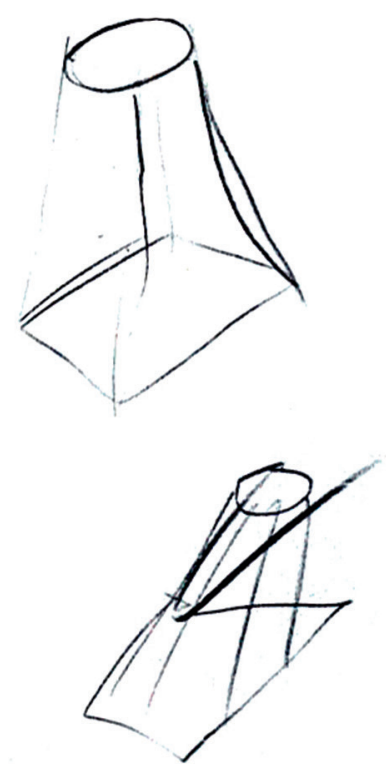

Figura 2. Primeros esquemas realizados por Le Corbusier en 1961. Fuente: Franmpton \& Kolbolwski (1981, P. 35).

${ }^{2}$ Esta versión se encuentra en el archivo de la Fundación Le Corbusier (en adelante (c) FLC), con el número de registro

U1191. En lo sucesivo, los códigos de este tipo corresponden a la identificación asignada por el archivo de la Fundación a los documentos a que se hace referencia.

\section{El programa arquitectónico}

Para iniciar el proyecto de la iglesia parroquial de Saint-Pierre de Firminy-Vert, Le Corbusier requirió, ante todo, un programa. El 19 de junio de 1960 recibió una versión inicial por parte de su cliente, la Asociación Parroquial de Firminy-Vert² ${ }^{2}$ Este documento se resume en dos partes. La primera, centrada en el coro y el órgano musical, se estructura bajo ocho títulos relacionados con la iglesia y el centro parroquial. La segunda consta de cuatro títulos que además de complementar lo concerniente al centro parroquial se refieren a las salas de reunión. Finalmente, una breve nota escrita a mano hace precisiones en cuanto a la iluminación, tanto durante el día como en la noche. A pesar de las explicaciones proporcionadas, al arquitecto esta versión le pareció poco detallada. 


\section{${ }^{3} \subset$ FLC. U1199.}

${ }^{4}$ C FLC. U119188: Descripción de la Iglesia parroquial de Saint-Pierre de Firminy-Vert en 1964. En este documento se lee: “(...) Le bâtiment c'est un prisme carré (...) portant une coque mince $(\ldots)^{\prime \prime}$.

${ }^{5}$ Según el capítulo I de la Constitución Sacrosanctum Concilium, aprobada en 1963 por el Concilio Vaticano II:

Se considera la liturgia como el ejercicio del sacerdocio de Jesucristo. En ella, los signos sensibles significan y cada uno a su manera realiza la santificación del hombre, y así el Cuerpo místico de Jesucristo, es decir, la cabeza y sus miembros, ejerce el culto público íntegro. En consecuencia, toda celebración litúrgica, por ser obra de Cristo sacerdote, y de su cuerpo, que es la Iglesia, es acción sagrada por excelencia, cuya eficacia, con el mismo título y en el mismo grado, no la iguala ninguna otra acción de la Iglesia. (Pablo VI, 1963).

${ }^{6} \mathrm{El}$ centro pastoral de Domenieani, fundado en 1937, creó las Ediciones de Cerf, con las que editó también la Revue de pastorale liturgique, la cual se convirtió en abanderada del movimiento litúrgico.
Ocho meses más tarde, el 11 de febrero de 1961, llegó a manos de Le Corbusier una segunda versión ${ }^{3}$ que se convirtió en el punto de partida del proyecto y puede considerarse como el segundo programa. Este se divide también en dos partes: la primera comprende títulos acerca de la iglesia en sí, en tanto la segunda se enfoca en el centro parroquial. Los títulos y las dependencias se detallan en unidades y cantidades, sin embargo, no se especifican las superficies ni las áreas de cada espacio (Chaverra, 2010). De la estructura de este segundo programa se desprende la idea de organizar el proyecto en dos secciones: una destinada a la iglesia junto con las salas y otra al centro parroquial y la sacristía. Tal organización favoreció la composición basada en dos formas opuestas: la cáscara como contenedora de la iglesia y el prisma como contenedor del centro parroquial ${ }^{4}$ (figura 3).

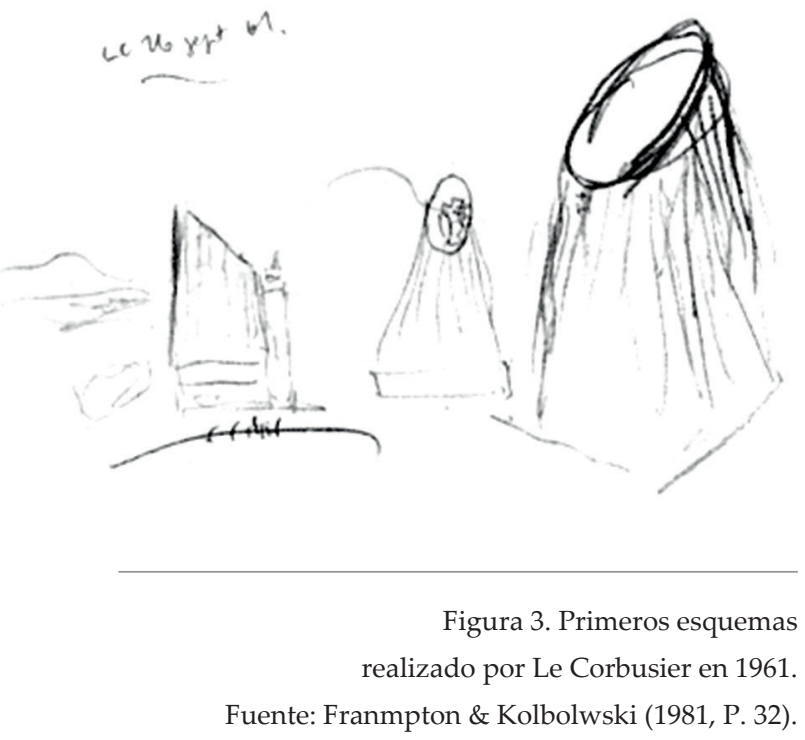

Puede decirse que existe cierto paralelismo entre la disposición del programa arquitectónico y los primeros esquemas elaborados por Le Corbusier, en los cuales el uso de las formas y las figuras geometrías son elementos claves en la composición. Esta constante se verá en las distintas interfases del primer proyecto.

El encargo de la iglesia demandó una especial atención de las funciones litúrgicas 5 . Para examinar esta tarea, L'Art Sacré es una referencia imprescindible. El 23 de octubre de 1960, Le Corbusier recibió los números 1 y 2 de esta revista en una edición titulada "Le lieu de la célébration", publicada en París por las Ediciones de Cerf en septiembre de aquel año ${ }^{6}$ (figura 4). En la publicación, el arquitecto hizo anotaciones que demuestran su interés por incorporar las funciones pertinentes. 

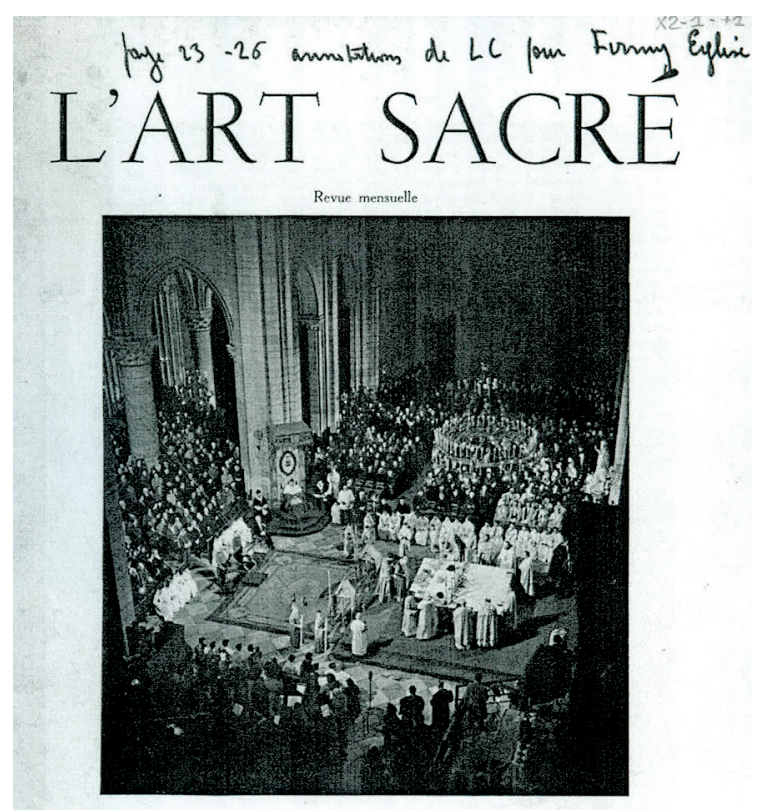

\section{LE LIEU DE LA CÉLÉBRATION}

I - Les données historiques et actuelles

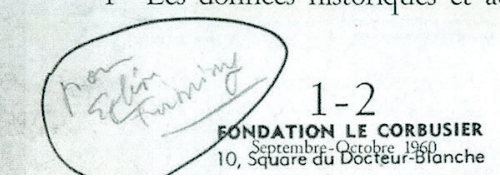

Figura 4. Portada de la revista L'Art Sacré, nros. 1-2, 1960. Fuente: ( FLC. X2171/13.

La anotación "pour Église Firminy", escrita en la portada, manifiesta que la revista fue tomada como referencia para el encargo. En el interior, Le Corbusier señaló fragmentos del artículo titulado "Pour les églises de notre temps", escrito por Joseph Gelineau. Este documento refleja de forma clara el debate preconcilio relativo a cómo debían ser las construcciones de las nuevas iglesias en Francia. En sus argumentos, Gelineau (1960) cuestionó el desorden generado por la distinción entre únicamente dos zonas (santuario y nave) en los nuevos templos. Propuso entonces seis zonas que, tradicionalmente, habían constituido el espacio de la asamblea: santuario, 
presantuario, coro, asamblea, comunión y accesos. Según el autor, estas áreas debían ser cuidadosamente examinadas y estudiadas en función de la liturgia, por lo tanto, ofreció una descripción rigurosa de ellas. El santuario, definido como la sede del celebrante y compuesto por el altar, el lugar de la lectura y el púlpito, fue ilustrado con imágenes del santuario exterior de la Capilla de Ronchamp (figura 5).

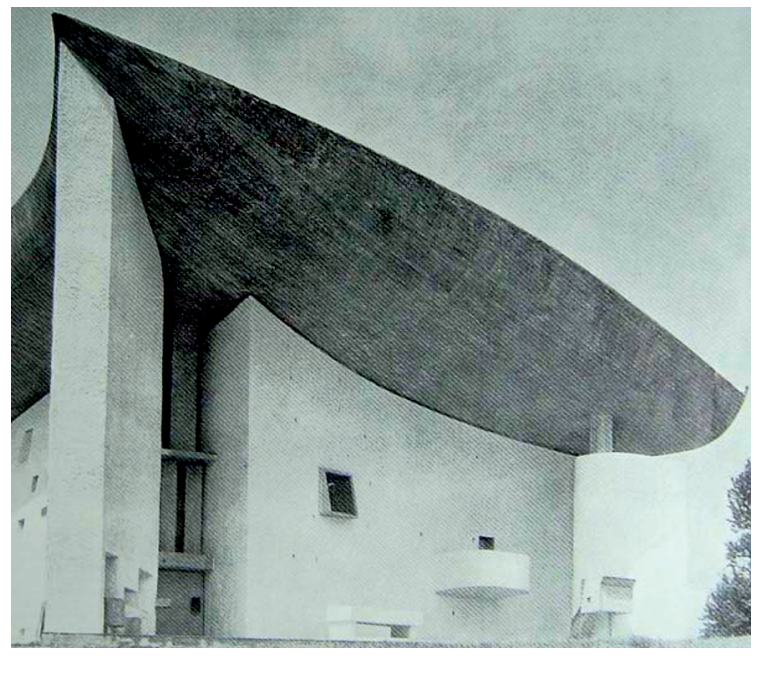

Figura 5. Santuario exterior de la Capilla de Ronchamp. Fuente: Gelineau (1960, p. 26).

El presantuario, lugar propio del diácono, se sitúa entre tres y cinco escalones más altos que la nave y un escalón más abajo del santuario. Este espacio de transición entre el santuario y la nave, destinado a unir el área de comunión de los fieles, es necesario para la ceremonia de los ministros inferiores que asisten directamente al 
celebrante, quien posee funciones de conductor y asistente de la asamblea. A partir del Concilio Vaticano II fue suplido por un personaje nuevo, el comentador, que puede desempeñar sus tareas en el santuario, el púlpito, la san-ta mesa o la nave. Además, debe ser visto por el público pero nunca ocupa una función en el santuario. La referencia en este caso fue la basílica San Marco de Venecia (figura 6).

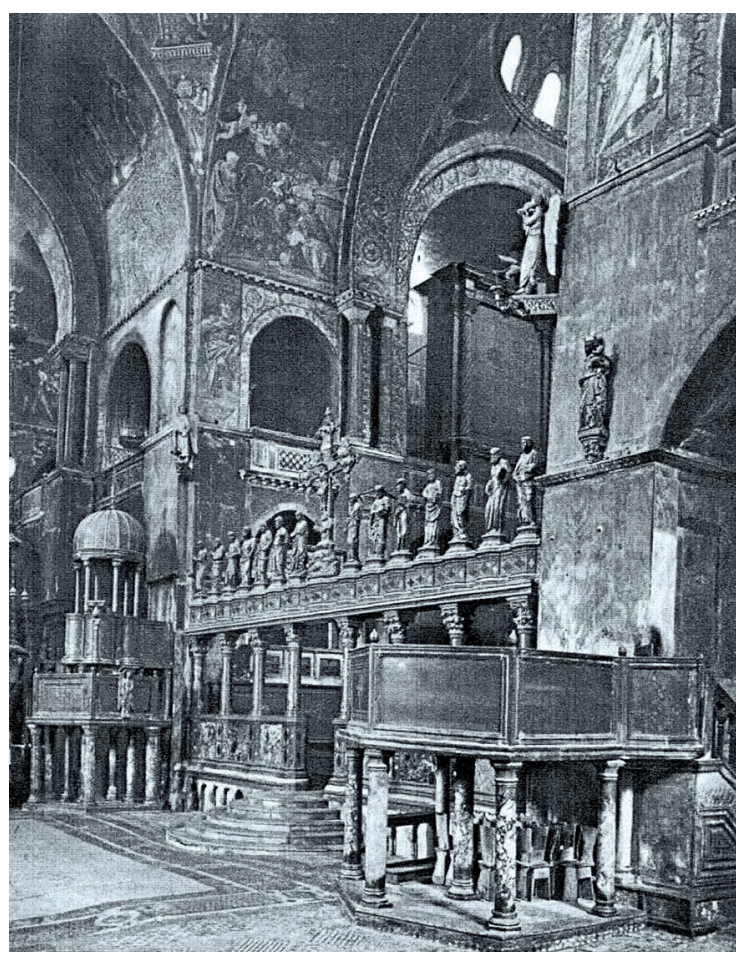

Figura 6. Basílica San Marco de Venecia. Fuente: @ FLC. X2171/13.

El coro, según la función litúrgica, se ubica delante del altar y del presantuario o en la cabeza de la nave. Para Gelineau, quienes cantan allí deben ser, principalmente, cantantes profesionales, y en segunda instancia niños y jóvenes de la comunidad que sin tener una habilidad musical especial se comprometan a dar un apoyo a la liturgia con su voz. Las parroquias suelen emplear los dos últimos grupos, tanto 
con hombres como con mujeres. El coro, en un punto intermedio entre el santuario y la nave, sirve para contener el sonido en un lugar elevado. Un ejemplo fue nuevamente la basílica San Marco de Venecia con su púlpito del siglo IX desarrollado en dos etapas: la primera para los cantores y la más alta para el diácono (figura 7).

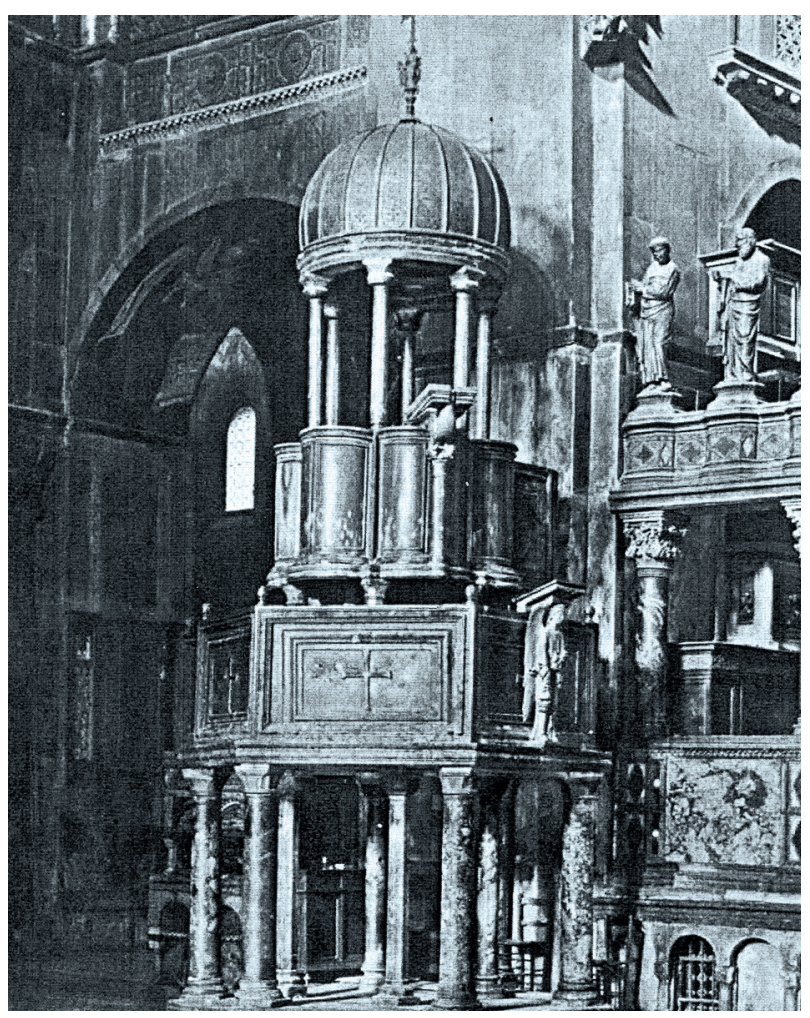

Figura 7. Basílica San Marco de Venecia con el púlpito del siglo IX. Fuente: @ FLC. X2171/13. 
La asamblea de fieles requiere un espacio homogéneo, que permita la libertad y en donde no se manifieste la individualidad sino más bien la expresión colectiva (figura 8). Igualmente, su estructura interna no debe ser circular con el altar central, pues esto distorsiona espacialmente la orientación de los feligreses hacia el altar. Además de las misas dominicales, Gelineau subrayó la necesidad de celebrar las ceremonias de menor capacidad o las misas semanales en la asamblea.

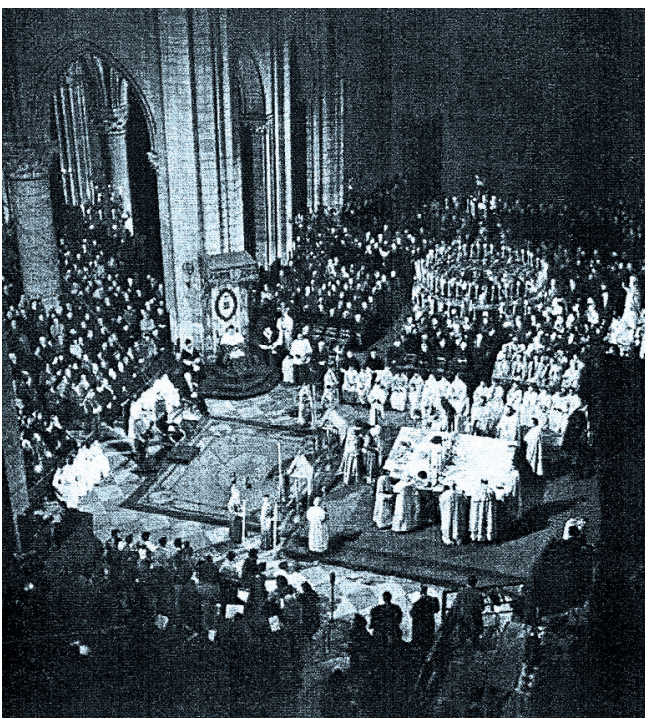

Figura 8. Asamblea de una iglesia, imagen publicada en la portada de L'Art Sacré, nros. 1-2.

Fuente: (C) FLC. X2171/13.

La zona de acceso es definida como la transición del mundo profano al mundo de los misterios. Se ubica entre la calle y el santuario, con un espacio que cumple funciones orientadas a favorecer la comunicación entre el espíritu de la familia parroquial y los participantes en la comunión. Los accesos deben anteceder el atrio, lugar destinado a informar sobre las actividades del centro (figura 9). 


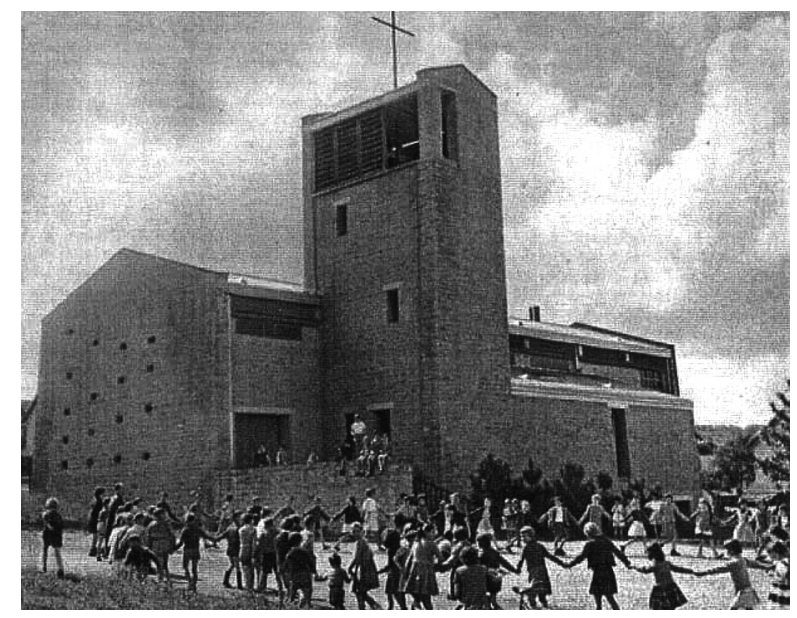

Figura 9. Acceso de la capilla Sainte-Thérèse en Doubs, imagen publicada en L'Art Sacré, nros. 1-2, p. 28.

Fuente: ( FLC. X2171/13.

Gelineau también precisó la ubicación de la capilla de semana, destinada a misas semanales y ceremonias pequeñas. A su vez, las múltiples referencias de púlpitos, con los ejemplos del existente en Saint Apollinare Nueva en Ravenne (figura 10), los de las basílicas de Saint Laurent en Roma (figura 11) y de San Marco, y el púlpito exterior de la Capilla de Ronchamp, fueron tenidas en cuenta por Le Corbusier.
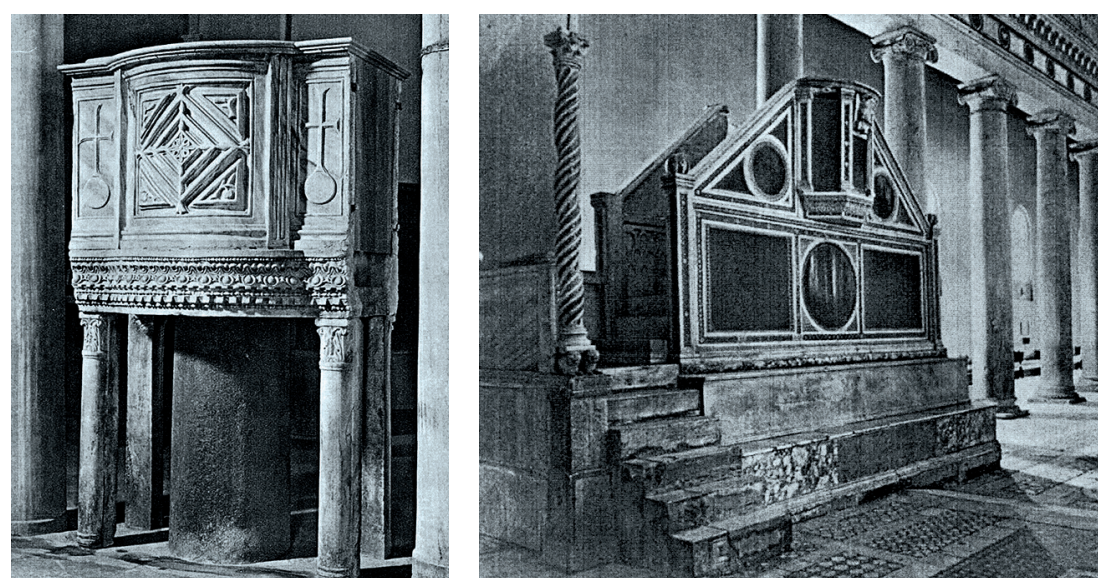

Figura 10. Púlpito de Saint Apollinare Nueva en Ravenne, imagen publicada en L'Art Sacré, nros. 1-2, p. 20 Figura 11. Púlpito de la basílica Saint Laurent en Roma, imagen publicada en L'Art Sacré, nros. 1-2, p. 21 
De las seis zonas esenciales propuestas por Gelineau, Le Corbusier centró su interés en el coro y en la idea de las misas cantadas. En consecuencia, la acústica adquirió especial relevancia, lo cual se vio reflejado en la forma del volumen adoptado por la iglesia y en la posición que ocupó el coro en el desarrollo del proyecto, tal y como lo testimonian los primeros esquemas (figura 12).

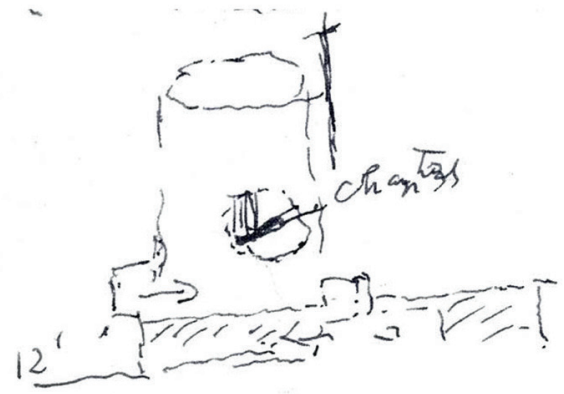

Figura 12. Dibujo de los primeros esquemas del proyecto en 1961, con el coro señalado. Fuente: @ FLC C. R64. - 757.

\section{PRIMEROS ESQUEMAS DEL PROYECTO}

Los primeros esquemas son dibujos derivados del programa arquitectónico y de las funciones litúrgicas. La composición inicial en torno a la idea de dos partes con un énfasis en la forma acústica es representada por Le Corbusier en su libreta de apuntes "carnet", en la que proyectó la iglesia (Franclieu, 1982) (figura 13).

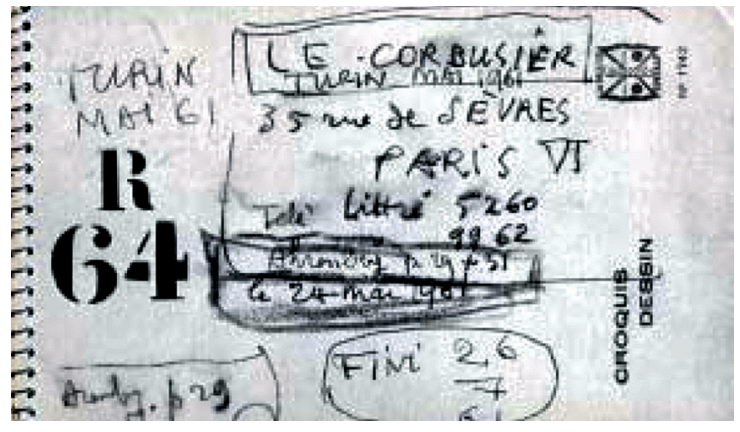

Figura 13. Libreta "carnet" con los primeros dibujos del proyecto de la iglesia de Firminy-Vert. Fuente: (c) FLC. C. R-64. 
En los croquis iniciales de junio de 1961, Le Corbusier dibujó en su libreta un volumen en tres fases: alzado, planta y sección, junto con las palabras "eau pluie" (Franclieu, 1982) (figura 14). La composición a priori de un volumen vertical, planta cuadrada y sección en forma cónica guarda analogías compositivas y programáticas con el dibujo correspondiente al proyecto de otra iglesia, la de Tremblay (figura 15).
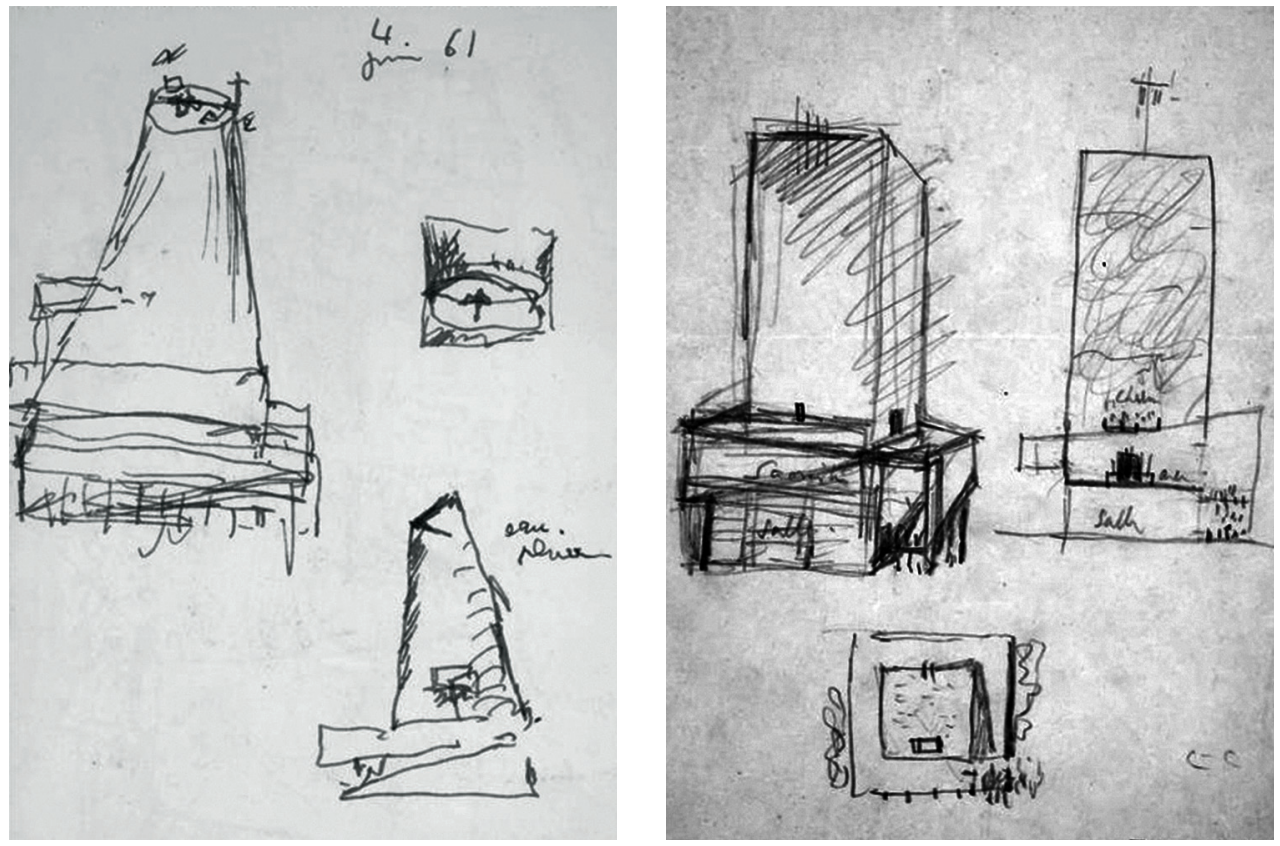

Figura 14. Dibujos de volumen, planta y sección de la iglesia de Firminy-Vert, realizados por Le Corbusier en 1961.

Fuente: () FLC. C. R64 - 749.

Figura 15. Dibujo de volumen, sección y planta de la iglesia de Tremblay, realizado por Le Corbusier en 1929.

Fuente: ( ) FLC. 32267. 
El proyecto de Tremblay fue un encargo de 1929 promovido por Gabrielle de Monzie (Frampton, 2000), una de las propietarias de la Ville Stein-Monzie (Boesiger, 1985). Esta iglesia, ubicada en las afueras de París (en Saint-Denis) presentó un programa arquitectónico organizado en dos niveles: el centro parroquial y la iglesia más el coro (figura 16). Tal orden es similar al planteado en el programa de Firminy-Vert.

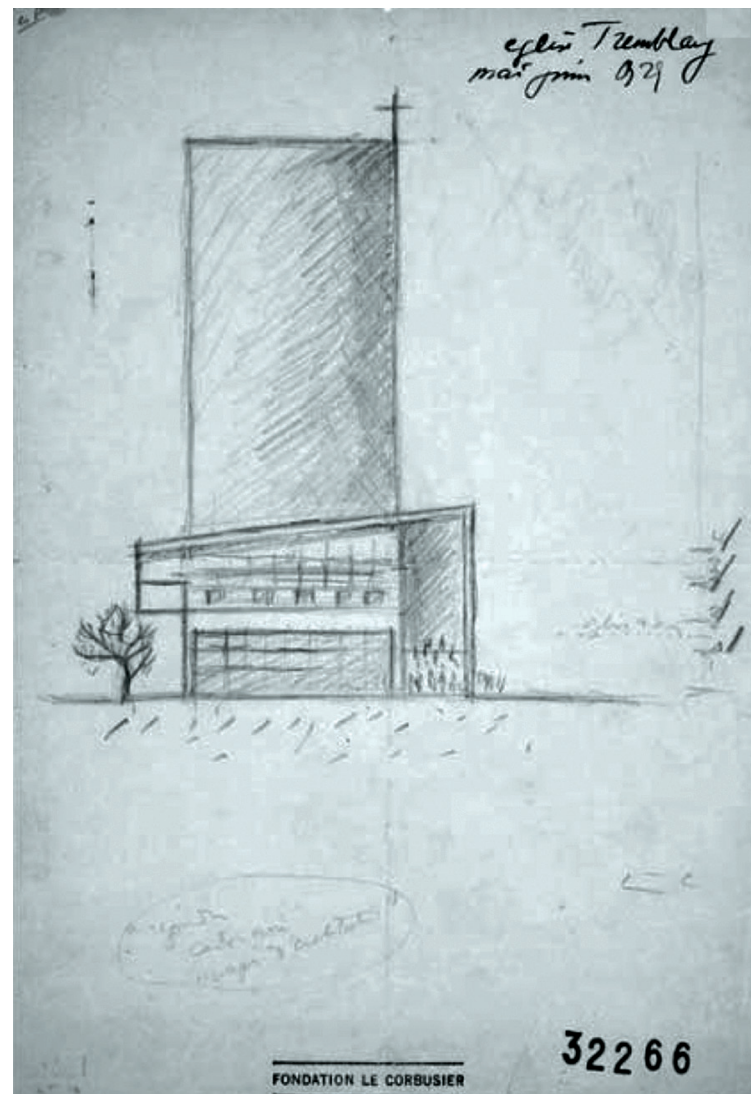

Figura 16. Dibujo de alzado de la iglesia de Tremblay, realizado en 1929. 
Ambos proyectos se componen a partir de una planta de superficie cuadrada con el altar ubicado en el costado este, alrededor del cual se circula a través de una rampa perimetral en forma de espiral. En el caso de Tremblay, el recorrido se inicia desde el vértice noreste de la planta hasta acceder al recinto de la iglesia por el extremo oeste, mientras que la rampa continúa hasta llegar a la tribuna del coro en el costado norte (figura 17). En Firminy-Vert el recorrido comienza en el vértice suroeste para alcanzar al recinto de la iglesia en el vértice noroeste (figura 18).
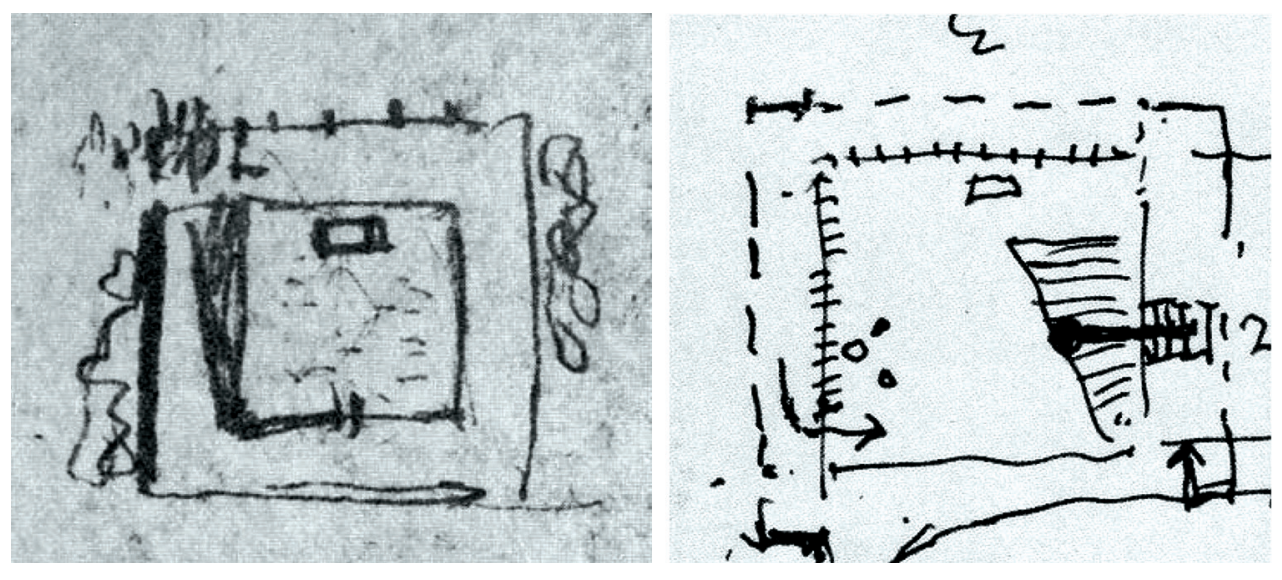

Figura 17. Dibujo girado $180^{\circ}$ de la planta de la iglesia de Tremblay.

Fuente: @ FLC. 32267.

Figura 18. Esquema de la planta de la iglesia de Saint-Pierre de Firminy-Vert en 1961. Fuente: Franmpton \& Kolbolwski (1981, P. 32). 
El paralelismo entre ambos proyectos se visualiza también en la sección y el alzado. La gran altura entre el nivel de la iglesia y la cubierta con el coro que ocupa una posición intermedia y sobreelevada insinúa la idea espacial de una amplia caja de luz sonora, como se observa en la imagen que muestra los dos proyectos (figura 19).
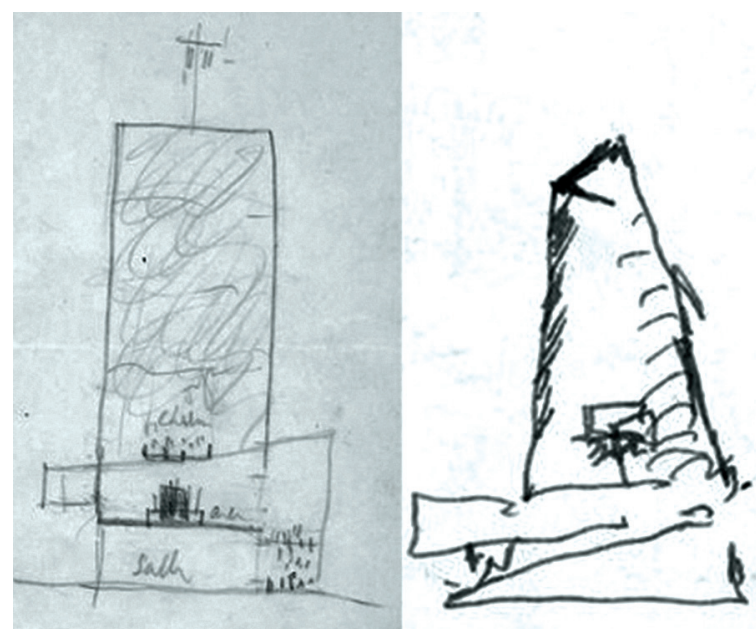

Figura 19. Dibujo de sección de las iglesias de Tremblay y Firminy-Vert . Fuente: elaboración propia a partir de los dibujos (c) FLC. 32267 y (c) FLC. C. R64 - 749.

El alzado y el volumen resaltan la forma cerrada y compacta del prisma cuadrangular en la iglesia parroquial de Tremblay, al igual que la forma cónica y cóncava en Firminy-Vert. La rampa perimetral enfatiza en sus bases la circulación en espiral en torno a un elemento vertical, siendo esta una de las cualidades principales en ambos esquemas, como se aprecia en la figura 20. 


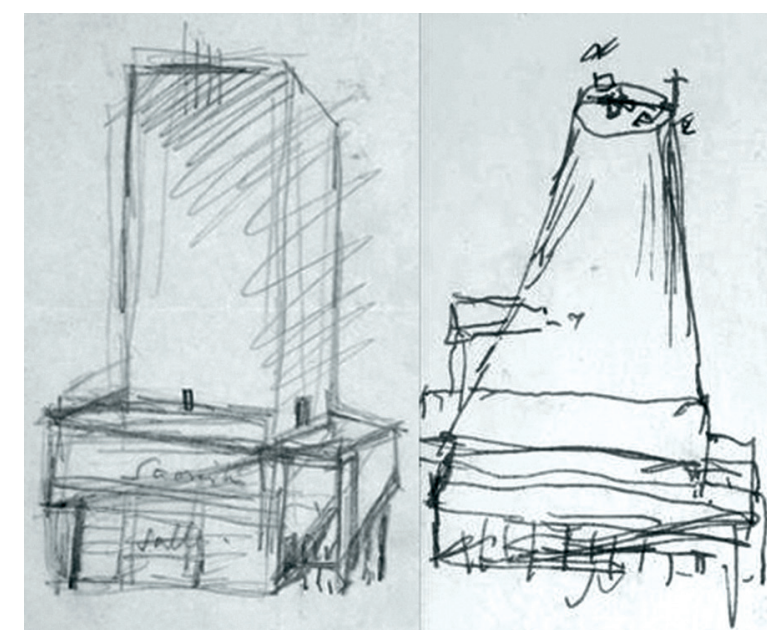

${ }^{7} \odot$ FLC. U11917. En estos

dibujos se lee: P. J.: EG-FIR. №

5756 - Implantation de $I^{\prime}$ Eglise - dessin de L-C. Ech: 1/500 - le 10 juin 1961. EG-FIR. № $5757-$

Plan de l'Eglise - dessin de L-C. Ech: $5 \mathrm{~mm} / \mathrm{m}$ - le 10 juin 1961. EG-FIR. № 5758 - Coupe générale de l'Eglise - dessin de L-C. Ech: $5 \mathrm{~mm} / \mathrm{m}$ - le 10 juin 1961.
Figura 20. Dibujo del volumen-alzado de las iglesias de Tremblay y Firminy-Vert . Fuente: elaboración propia a partir de los dibujos @ FLC. 32267 y @ FLC. C. R64 - 749.

La similitud con la organización del programa y el concepto formal espacial de la iglesia de Tremblay la convierten en un referente comparativo con Saint Pierre de Firminy-Vert, como también en el punto de inicio para este proyecto. Así queda demostrado con la estampa del sello de goma "EG FIR I" en la imagen de la iglesia de Tremblay, aparecida en el número 34 de la revista Chiesa \& Quartiere, dedicada enteramente a la iglesia de Firminy-Vert. El sello corresponde a los dibujos y planos de la primera versión de esta y se usó para identificar las versiones siguientes.

La composición inicial de la propuesta de Firminy-Vert se sustentó en dos premisas conceptuales. Por una parte, la organización del programa en dos secciones (iglesia y centro parroquial). Por otra parte, el papel del coro y por ende el protagonismo otorgado a la acústica al proyectar la estructura del edificio. Ambas premisas tienen como referencia la iglesia de Tremblay, esbozada como una planta cuadrada con altar orientado al este y una rampa perimetral concebida para girar en torno al crecimiento de un prisma cuadrangular. Con esas bases se iniciaron los esquemas en que se proyectaron, dibujaron y esbozaron distintas formas geométricas que se complementan, transforman y oponen en el desarrollo proyectual. Este conjunto puede considerarse el primer proyecto de Firminy-Vert, integrado por cuatro dibujos de emplazamiento, planta, corte y perspectiva ${ }^{7}$ que fueron entregados oficialmente por Le Corbusier el 7 de julio de 1961 a Eugène Claudius-Petit. 


\section{Emplazamiento general ${ }^{8}$}

Se planeó emplazar la iglesia en el extremo oeste de la zona deportiva', sitio escogido por Le Corbusier en su tercera visita a Firminy-Vert, según quedó consignado en el carnet identificado por Franclieu (1982) como P61, números 581 a 583. En la figura 21 se aprecia el croquis con un planteamiento general de equipamientos que incluye la iglesia, el estadio, la gradería y la casa de cultura.

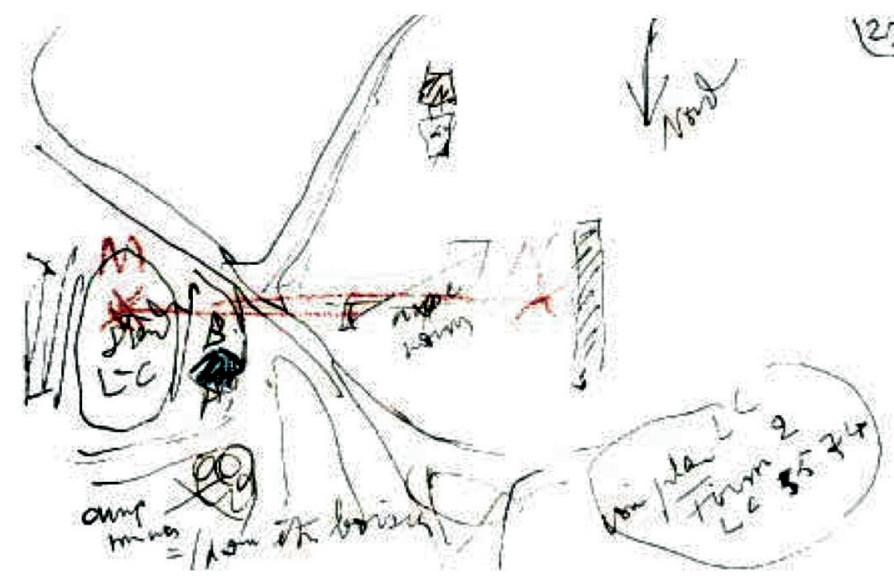

${ }^{8}(\mathrm{C})$ FLC. 16540.

${ }^{9} \odot$ FLC. U11917. El dibujo correspondiente dice: “L’Église est installée à l'extrémité ouest du terrain de sport".

${ }^{10} \odot$ FLC. 17245.
Inicialmente, el plan director de urbanismo de Firminy-Vert ${ }^{10}$ destinó la zona dos a usos deportivos y culturales, aunque contempló un posible uso religioso. Así, la primera propuesta del plan ${ }^{11}$ planteó un conjunto deportivo para la zona (figura 22). 


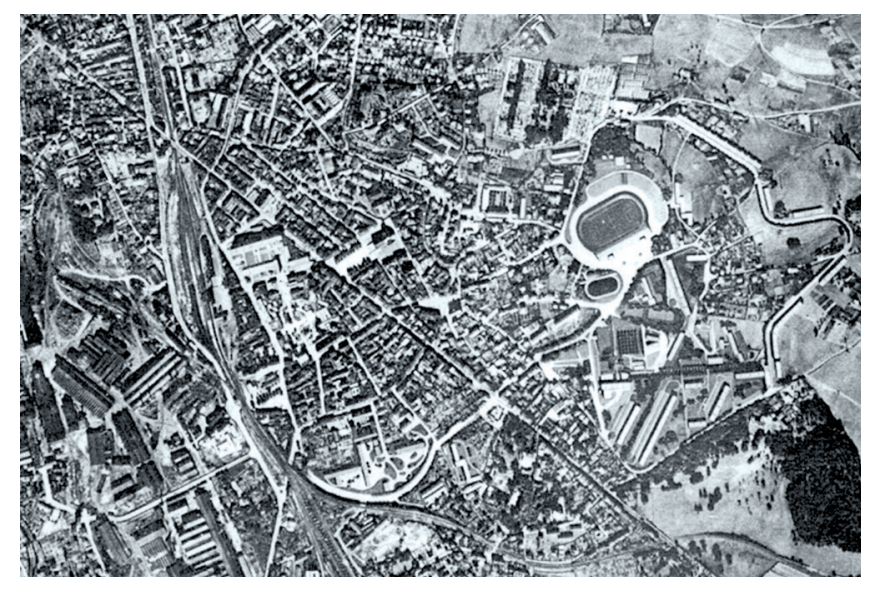

Figura 22. Fotomontaje del plan de Firminy-Vert en 1955. Fuente: Urbanisme. Revue Française, 1968, núm. 104, p. 56.

Posteriormente, cuando se asignó el encargo de la casa de la cultura y el estadio el emplazamiento fue modificado. Se mantuvo la zona deportiva existente, para lo cual se dispuso el trazado de un anillo perimetral que abarcara y contuviera todo el conjunto $^{12}$. Cabe anotar que la topografía de una vieja cantera condicionó el trazado perimetral del bulevar y de los niveles del conjunto de equipamientos (figura 23).

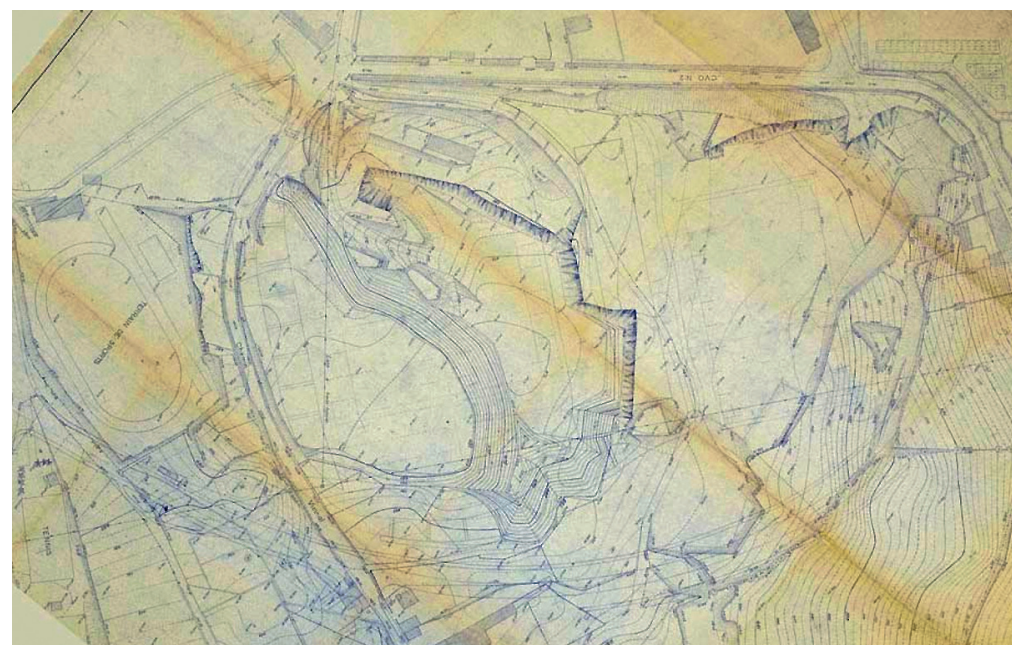


Le Corbusier tomó como base un plano para realizar el primer emplazamiento del proyecto de la iglesia de Firminy-Vert (figura 24). En 1958 la zona deportiva existente fue modificada por la administración local de Firminy que decidió incorporar en estos terrenos otros equipamientos, como la piscina y la iglesia ${ }^{13}$.

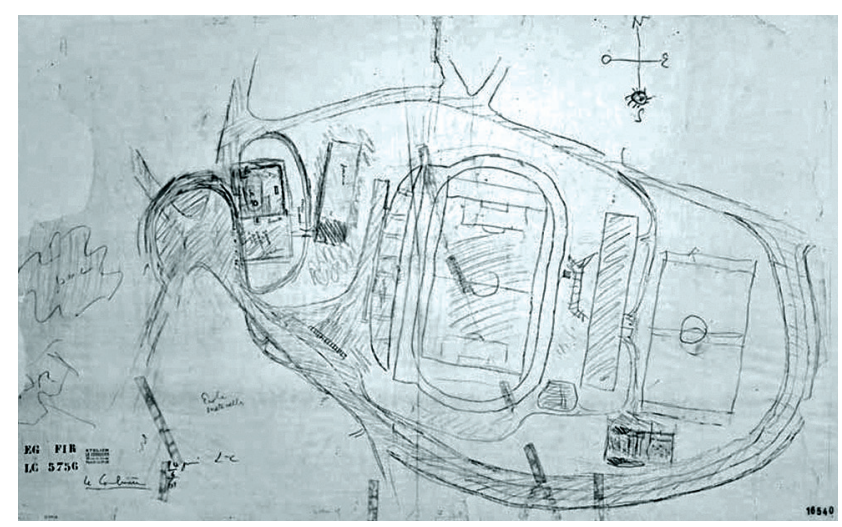

Figura 24. Dibujo del emplazamiento de la primera versión. Fuente: (C) FLC. 16540.

${ }^{13}$ Plano $@$ FLC. 16761, elaborado por la empresa Maurins \& Magand y tomado por Le Corbusier como base para realizar el primer emplazamiento.

${ }^{14} \odot$ FLC. 16533.

${ }^{15} \odot$ FLC. 16588.
El dibujo del primer emplazamiento (figura 24) sorprende por la desalineación entre la iglesia y los demás equipamientos del conjunto. El desconcierto se agrava aún más si se hace una comparación con la orientación de los puntos cardinales del dibujo. Esta desalineación puede explicarse por la correspondencia existente con la orientación del emplazamiento de la antigua zona deportiva, representada en un dibujo $^{14}$ elaborado para el estudio de cotas, niveles y pendientes. En este dibujo se aprecia como el emplazamiento de la iglesia coincide con el de esa antigua zona. Si se observa otro dibujo ${ }^{15}$, surge una posible explicación adicional para la desalineación, relacionada con la idea de incorporar un aparcamiento en el costado oeste. Un dibujo más ${ }^{16}$ muestra una modificación de la alineación, de manera que coincide estrictamente con la orientación de los puntos cardinales (figura 25). 

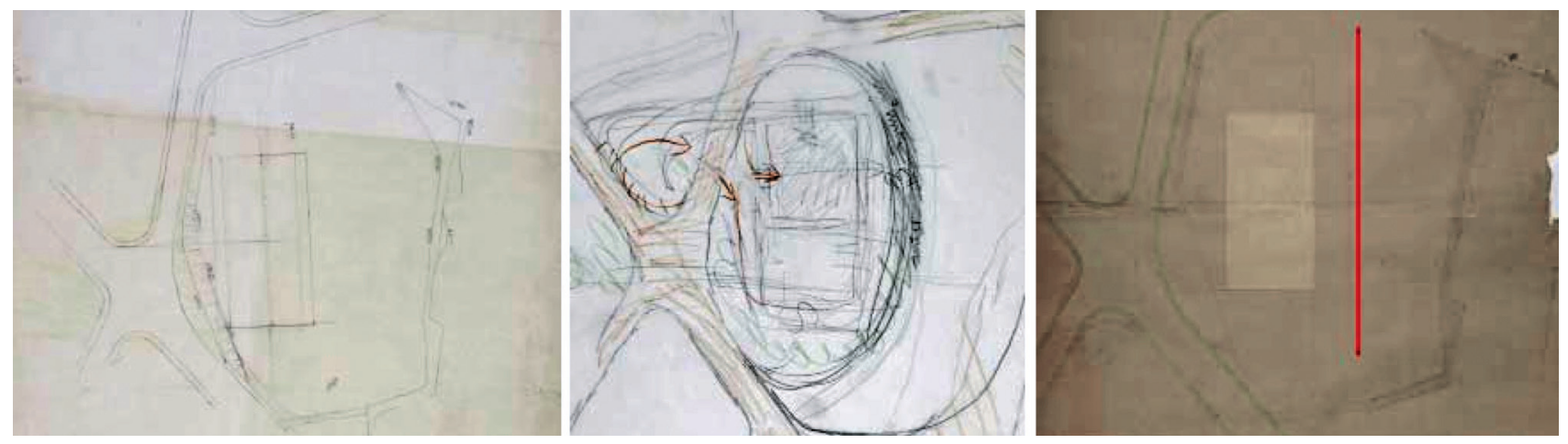

Figura 25. Emplazamiento de la iglesia con la zona deportiva y la alineación de los puntos cardinales

Fuente: elaboración propia a partir de los dibujos . (c) FLC. 16533, (c) FLC. 16588, (c) FLC. 16559.

\section{Planta general}

Le Corbusier dibujó en un papel calco de $0.75 \mathrm{~cm} \times 1.10 \mathrm{~cm}$ una planta única de la iglesia ${ }^{17}$, compuesta por una superficie rectangular, orientada en sentido norte-sur y dividida en dos superficies cuadradas. En cada una de ellas se desarrolla parte del programa arquitectónico, que es complementado con la información ofrecida en sección. Estos dos dibujos concentran toda la esencia del proyecto (figura 26).

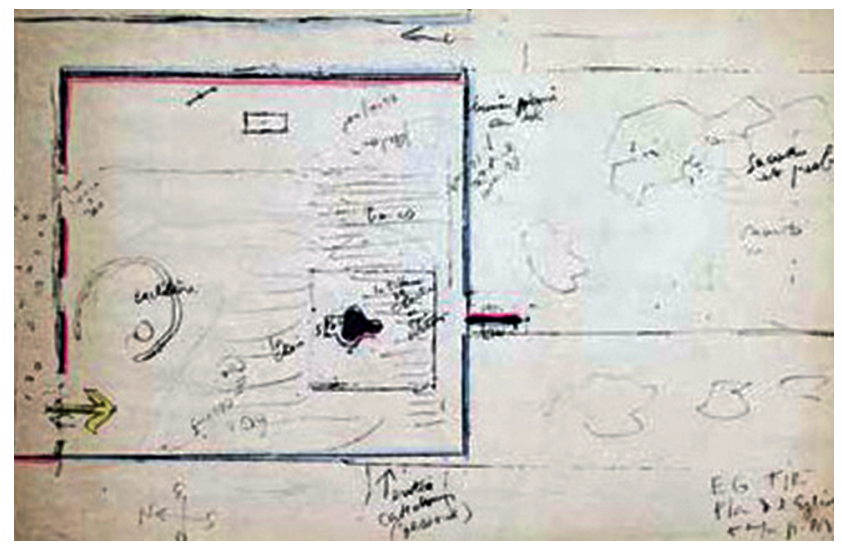

Figura 26. Dibujo de la planta general de la primera versión. Fuente: () FLC. 16654. 
La planta rectangular se divide en dos cuadrados de $30 \mathrm{~m}$ x $30 \mathrm{~m}$ cada uno. Hacia el norte aparece el recinto principal conformado por el altar, el bautisterio, el púlpito y el coro. Hacia el sur, el centro parroquial con la sacristía, la oficina de recepción, la vivienda auxiliar y el campanario. La planta de la iglesia se encaja en un recinto cuadrado, cuyo interior es fijado con el eje este-oeste del altar, el cual se ubica sobre la superficie rectangular del santuario junto con una cruz.

En la zona noroeste de la planta se sitúa el bautisterio, constituido por una tabiquería circular, con abertura de ingreso y fuente bautismal, junto a la puerta que da paso al recinto de la iglesia. Se crea así un juego compositivo entre el acceso por la rampa más el bautisterio y el acceso por la escalera más la tribuna del coro localizada en el extremo sur del recinto, tal como se muestra en la figura 27.

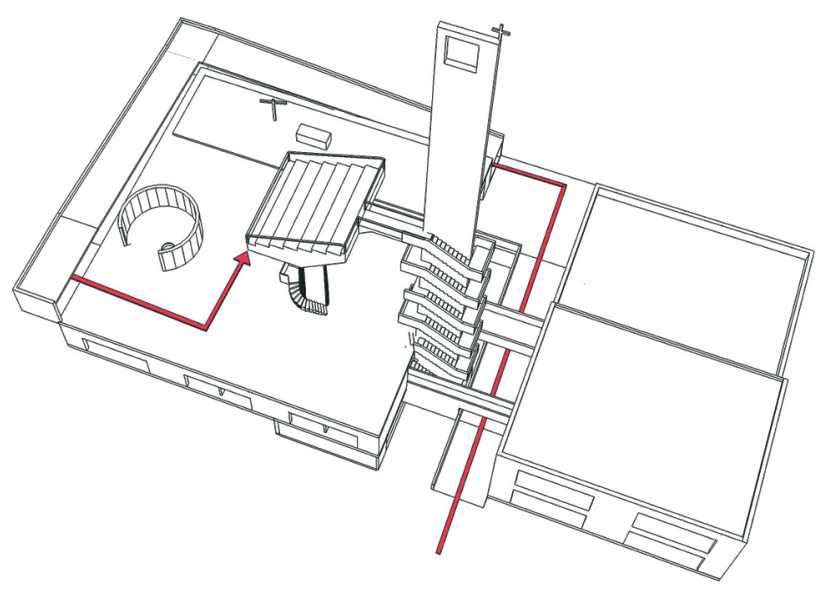

Figura 27. Isometría con la inmensa columna, el púlpito y la tribuna del coro. Fuente: autores. 
El púlpito del santo patrono y la tribuna del coro se soportan por un inmenso pilar ubicado en el extremo sur del recinto. Al púlpito se accede por unas pequeñas escaleras en forma de caracol. La tribuna, sostenida por la parte superior del pilar, está configurada en una superficie cuadrada con inclinación sur-norte, a la que se llega a través de escaleras independientes y externas, situadas por fuera del recinto. Aunque la planta del centro parroquial ofrece poca información, tres dibujos ${ }^{18}$ elaborados un mes después de la entrega brindan una mayor comprensión y desvelan cómo el proyecto se compuso y organizó en cuatro niveles desde su inicio

\section{Variante de la planta, nivel 1}

El nivel 1 del proyecto, destinado a aparcamiento y enrasado con la cota 477,06 de la vía, presentó desde el comienzo un problema en su implantación con la pendiente del terreno, lo cual afectó todo el proceso proyectual. Así se puede reconocer en el dibujo correspondiente a dicho nivel ${ }^{19}$ (figura 28). La planta se organiza a partir de la estructura de la escalera que sostiene el campanario y de la rampa que conecta con el segundo nivel. Estos dos elementos articulan los distintos niveles.

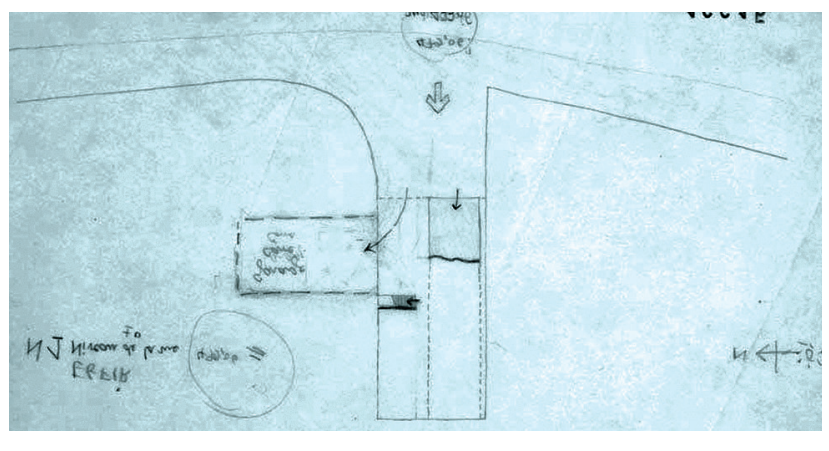

${ }^{18} @$ FLC. 16615, () FLC. 16531 y (c) FLC 16601.
Figura 28. Dibujo del nivel 1 de la iglesia Saint-Pierre de Firminy-Vert. Fuente: (c) FLC. 16615. 
Variante de la planta, nivel 2

El dibujo del nivel $2^{20}$ (figura 29) muestra por primera vez la distribución interior de la planta destinada a las salas y a las habitaciones de los vicarios y del cura. Se ve claramente cómo el vacío generado entre la rampa y la escalera divide la planta en dos partes. Aparecen las salas dispuestas en dos bandas paralelas, una apoyada en el costado este con la sala general, y otra en el costado oeste con las salas de catecismo. La circulación interna en forma de ele (L) se articula en el costado sur con la escalera del campanario y el pasadizo-puente que conecta con el centro parroquial. En la planta de este último parece apreciarse una división entre una zona para el cura, en el costado oeste, y un área para los vicarios en el costado sur.

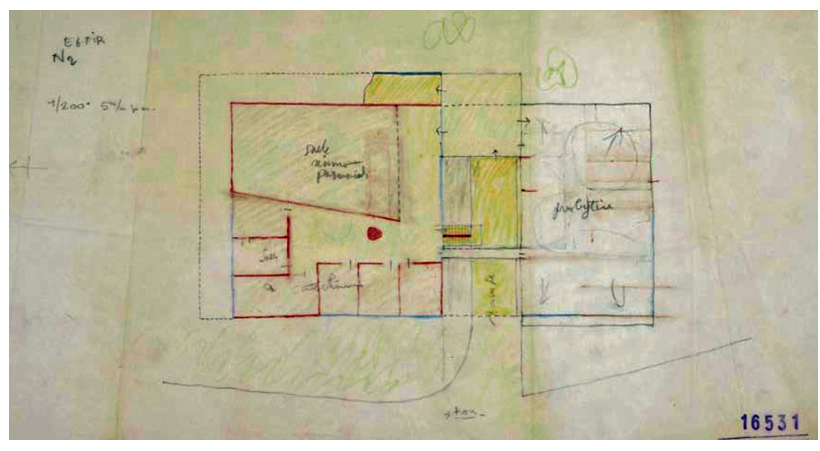

Figura 29. Dibujo del nivel 2 de la iglesia Saint-Pierre de Firminy-Vert.

Fuente: ㄷ FLC. 16531.

Variante de la planta, nivel 3

En el dibujo del nivel $3^{21}$ (figura 30), la iglesia y la sacristía se conectan a través de un puente. El recorrido desde la sacristía en el nivel 3 hasta la habitación del cura en el nivel 2 hace necesario el uso de las escaleras y el paso por la iglesia. Este mecanismo confirma la idea de articular todos los desplazamientos por medio de la escalera y las rampas, de modo que es preciso tener en cuenta la circulación como un elemento compositivo para el desarrollo del proyecto. 


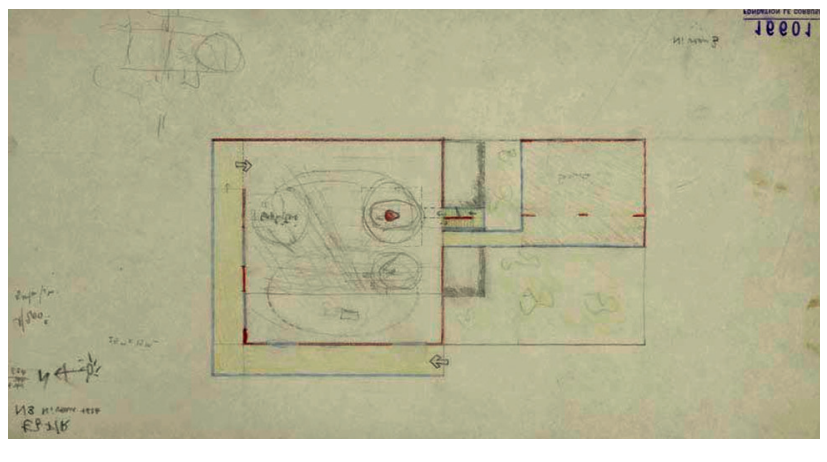

Figura 30. Dibujo del nivel 3 de la iglesia Saint-Pierre de Firminy-Vert . Fuente: ( ) FLC. 16601.

Otra característica del dibujo de este nivel es la proyección en la planta de una figura geométrica cercana a un ovoide en dos momentos distintos, pues se trata de una comprobación de la posición que debía ocupar la cubierta, la cual determina la forma del volumen que contiene la iglesia. La cubierta se dibujó inicialmente en el extremo este, sobre el altar ${ }^{22}$, pero la inclinación del volumen resultante en el costado oeste generaba una colisión con la tribuna del coro. El cambio al costado oeste resolvió el problema al quedar el ovoide sobre la tribuna y el bautisterio (figura 31).

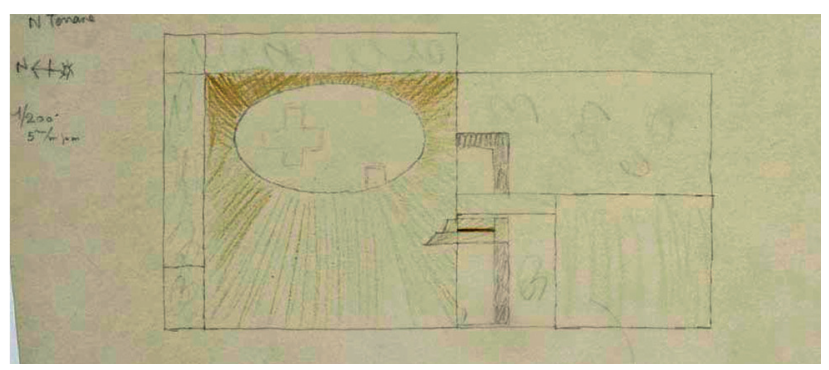

Figura 31. Variante de la cubierta de la iglesia Saint-Pierre de Firminy-Vert. Fuente: (c) FLC. 16647. 


\section{Sección general}

La sección general, dibujada en papel calco de $0,66 \mathrm{~cm} \times 0,84 \mathrm{~cm}$ y escala $1 / 200$ se organizó en cuatro niveles: aparcamiento; salas de catecismo y centro parroquial; iglesia y sacristía, y por último, la tribuna del coro $^{23}$. Esta disposición inicial se mantuvo a lo largo del proceso proyectual. Un dibujo en sección ${ }^{24}$ complementó el de la planta general al ofrecer información sobre la dimensión espacial del interior de la iglesia, la altura y forma de los volúmenes. El pilar por medio del cual se sostiene la tribuna y el campanario en que se apoyan las escaleras que conducen a esta son elementos arquitectónicos cuya presencia favorece la verticalidad de la sección. En la cubierta se destacan dos vanos descritos como óculos, uno en forma de cruz y otro cilíndrico, cuya función es ofrecer luz cenital al recinto (figura 32).

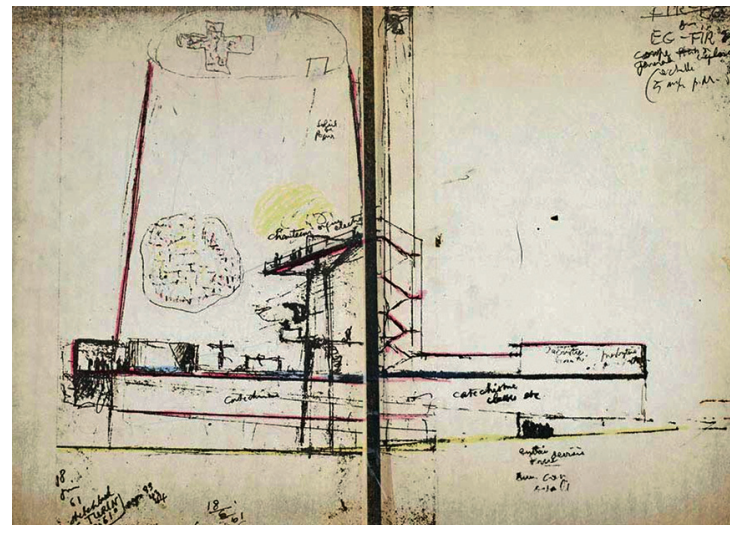

Figura 32. Dibujo del corte general de la primera versión.

Fuente: (C) FLC. 16608.

El esquema de junio 18 de $1961^{25}$ (figura 33) contiene los mismos elementos que el dibujo de la sección general. El esquema ya propone tres niveles más la tribuna del coro, mientras que las protagonistas del espacio interior son la acústica y la luz cenital. Con relación a esta última, dos aperturas en la cubierta, descritas como óculos 1 y 2 tienen formas distintas y cumplen funciones específicas de acuerdo con la posición y el movimiento del sol en cada época del año. El óculo cruciforme se orienta en la posición del astro durante el solsticio de invierno, en tanto el cilíndrico recoge la luz solar en el solsticio de verano. En cuanto a la acústica, la tribuna del coro se impone en el recinto interior. Se pone así de relieve la idea del coro arquitectónico, característica acuñada por Le Corbusier a partir de su conocimiento e investigaciones de las funciones litúrgicas y de esta zona en particular. 


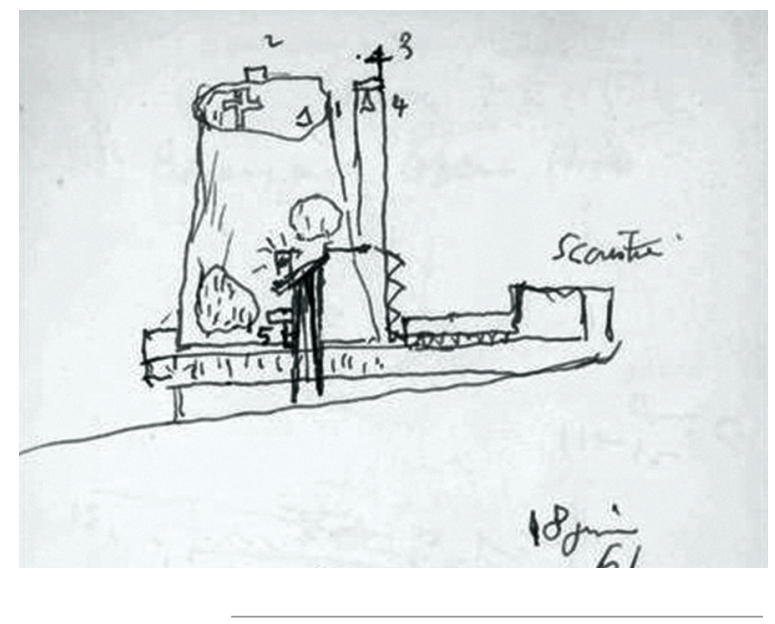

Figura 33. Esquema realizado por Le Corbusier el 18 de junio de 1961. Fuente: (C) FLC. C. R64 - 758.

\section{Variante de la sección general (norte-sur)}

El dibujo realizado el 11 de julio de $1961^{26}$ (figura 34) muestra, por un lado, los niveles, las alturas y la distribución del programa, y por otro, la estructura del campanario como elemento soporte de las escaleras y del volumen que cubre la iglesia. Estas cualidades no estaban clarificadas en el dibujo de la sección general.

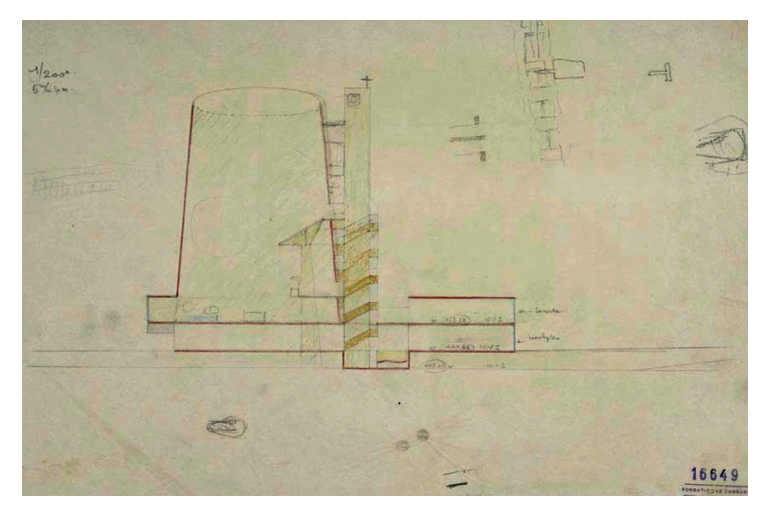

Figura 34. Dibujo de la variante del corte general de la primera versión. Fuente: @ FLC. 16649. 
El nivel 1 se determinó en la cota 477,06, con una altura aproximada de $2.60 \mathrm{~m}$ en relación con el terreno natural. El nivel 2 fue fijado en la cota 479,66, con una altura de 3.66 metros entre los forjados de los niveles 1 y 2 . Esta diferencia de altura sirvió de referencia en el forjado del nivel 3, establecido en la cota 483,32. El púlpito del santo patrono se situó en la cota 486,98 y el coro en la cota 497,96, la cual marcó a su vez el nivel 4. Estas cotas en los cuatro niveles definieron la proporcionalidad y la altura del volumen de la iglesia, cuya altura es de $32.94 \mathrm{~m}$ desde el forjado del nivel 3 y 36.60 m desde el forjado del nivel 2. La altura del volumen compensa la proporcionalidad entre la dimensión de la planta y la escala del volumen.

El campanario, arriostrado por varios elementos que operan como arbotantes entre esta estructura y el volumen de la iglesia, tiene una doble función. Por una parte, sirve de contrafuerte a dicho volumen. Su otra función, ya comentada, es soportar las escaleras que conducen a la tribuna del coro.

\section{Variante de sección (oeste-este)}

Un dibujo de lo que debía ser la fachada sur y la sección oeste-este ${ }^{27}$ presenta un estado inconcluso (figura 35). Sin embargo, este dibujo ilustra uno de los problemas capitales que repercutió en las cimentaciones, como fue la orientación respecto a la implantación, es decir, la relación entre el edificio y el terreno. Se aprecia como entre las rocas del costado este y el paramento de la fachada este se situó la plaza de la iglesia. A su vez, entre el anillo vial del bulevar y las fachadas norte, oeste y sur se dispusieron jardines, parterres y áreas libres. Otra particularidad del dibujo es la definición de la inclinación y la posición de la cubierta, las cuales se contradicen con lo observado en el dibujo de la planta de cubierta $^{28}$ en que la inclinación y la posición aparecen en el sentido contrario para permitir la ubicación de la tribuna del coro

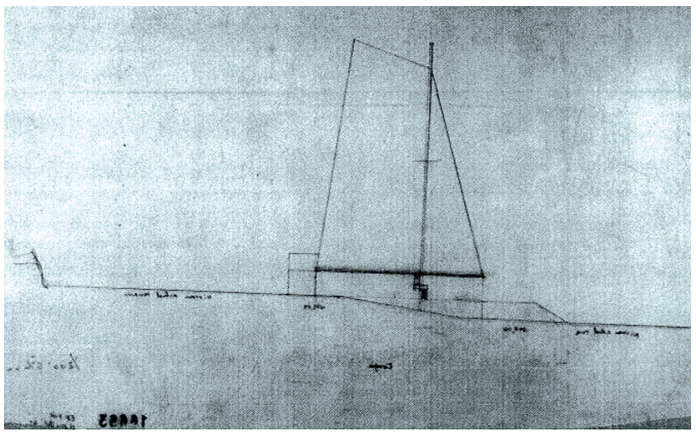


Variantes de la fachada oeste y de la fachada este

Los dibujos de la fachada oeste ${ }^{29}$ y de la fachada este ${ }^{30}$, pertenecientes al paquete realizado el 11 de julio de 1961, pueden valorarse como los primeros de la fachada. En el primero se estudia el desnivel existente entre la rasante del bulevar con la cota 477,06 y el nivel del terreno natural con las cotas 479,80 y 479,74 . Otro dibujo ${ }^{31}$ define el terreno natural en la cota 479,66 con relación a los posibles puntos de acceso en el costado sur, identificados con las cotas 478,87 y 480,24. El dibujo de la fachada oeste expresa una clara intención por incorporar un cerramiento opaco en el volumen de la iglesia y la sacristía, como también un cerramiento con vanos en la salas de catecismo y el centro parroquial, condición que se representa mediante el sombreado de los distintos niveles (figura 36).

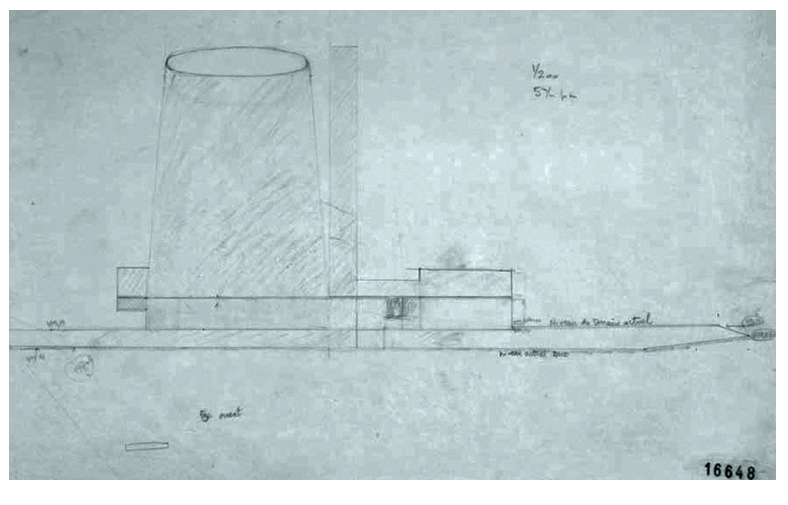

Figura 36. Dibujo de la variante de la fachada oeste, primera versión. 
La fachada este tiene las mismas características en los cerramientos (ciegos en el volumen de la iglesia y un poco más abiertos en el de la sacristía), como se aprecia en su dibujo correspondiente (figura 37). El centro parroquial es marcado con el nivel $+2,60$ respecto al nivel del semisótano, el cual solo puede verse en el mencionado dibujo del corte norte-sur ${ }^{32}$. La sacristía se marca con el nivel $+6,26$, altura muy superior a la indicada en dicho dibujo, pues en este se establece en 3,66 $\mathrm{m}$. Las cotas y los niveles que aparecen en la sacristía, al lado izquierdo del dibujo, causan confusión. Aun así, las contradicciones se deben a los desplazamientos y movimientos del proyecto. Al respecto, es habitual la disparidad entre los datos de dibujos distintos e incluso de uno solo, situación constante hasta el proyecto final.

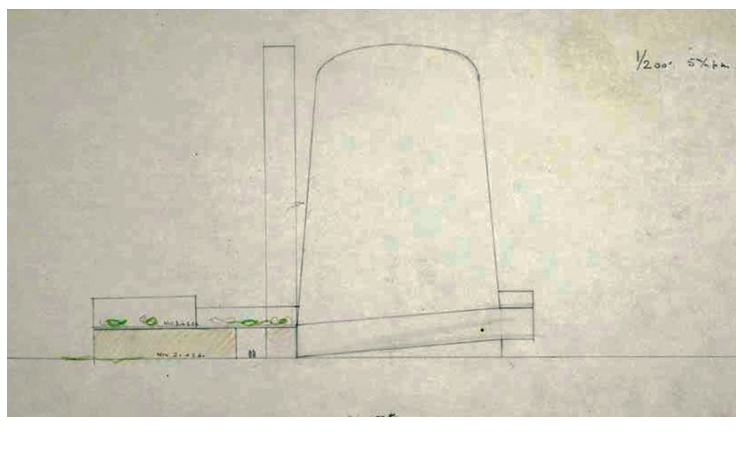

Figura 37. Dibujo de la variante de la fachada este, primera versión. Fuente: FLC. 16650.

Vista general

El 24 de junio de 1961 Le Corbusier trazó el primer esbozo en perspectiva del volumen de la iglesia ${ }^{33}$ y concibió una doble composición (la del paisaje y la del edificio). Escoge los inmuebles Sive-Roux, en dirección al cementerio, como punto de visión para el dibujo. Visualiza los niveles que estratifican el terreno, destaca las "rocas" como referencia para los equipamientos del estadio y la casa de la cultura y los puntos M y N que determinan las plataformas de la iglesia. Todo queda inscrito dentro del anillo vial del bulevar "camino real" y la futura ruta axial. También dibuja levemente, con lápiz de color azul, el perfil volumétrico de la iglesia. El suelo natural y la vegetación son azarosamente sombreados con color verde, en tanto el cruce de caminos entre el bulevar y el acceso a los inmuebles con amarillo (figura 38). 


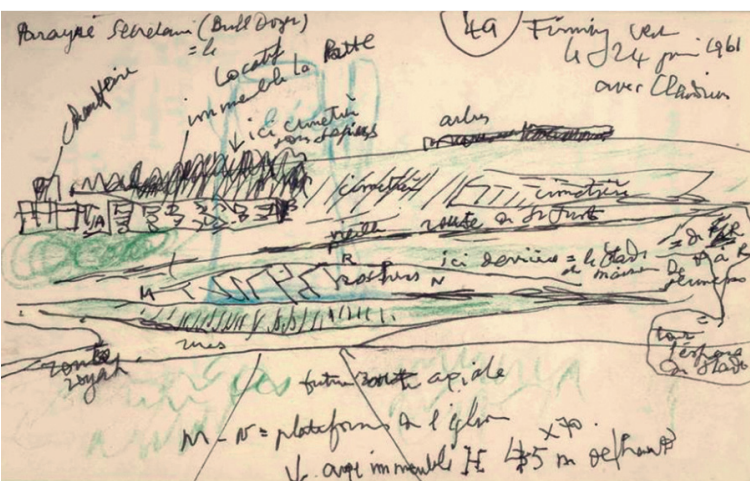

Figura 38. Dibujo realizado por

Le Corbusier el 24 de junio de 1961.

Fuente: @ FLC. 16651.

Este esbozo en perspectiva insinúa una estrategia compositiva. La verticalidad del volumen de la iglesia se contrapone con el horizonte accidentado del entorno para introducir la noción de un paisaje antagonista, basado en la vertical y la horizontal. Tal planteamiento ya está implícito en el croquis del 18 de julio de 1960 en el que dos ' $X$ ' señalan con una línea vertical el punto exacto del emplazamiento de la iglesia, en contraposición al paisaje montañoso del Macizo Central. Estas marcas componen el edificio, es decir, la ' $\mathrm{M}$ ' y la ' $\mathrm{N}$ ' del primer esbozo en perspectiva determinan la plataforma horizontal (centro parroquial) en tanto las ' $\mathrm{X}$ ' del croquis 
de 1960 definen el volumen vertical (iglesia). Entre ambos dibujos se descubre una composición transversal a través del paisaje antagónico y el edificio yuxtapuesto, esto es, una composición basada en el ángulo recto, cuestión tratada por el arquitecto en una de sus obras (Le Corbusier, 1955) como se ilustra en la figura 39.

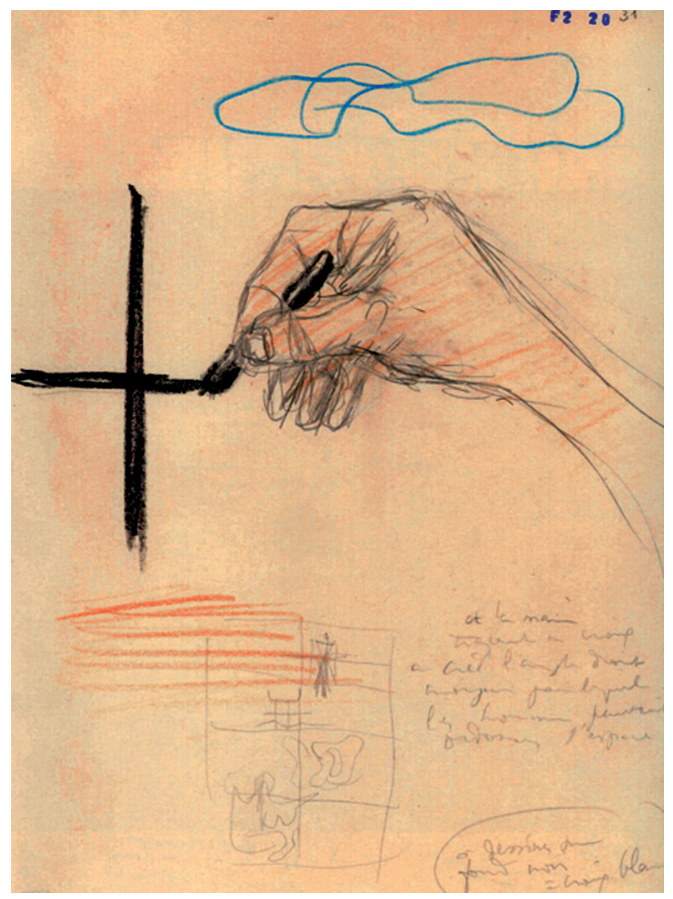

Figura 39. Boceto preparatorio para el libro Le poème de l'angle droit. Fuente: @ FLC. F2 2031. 


\section{RESTITUCIÓN GRÁFICA DEL PROYECTO}

A partir del análisis basado en archivos y fuentes gráficas originales del dosier de Le Corbusier, como también de un trabajo en que se estudia la iglesia de Saint Pierre de Firminy-Vert (Brooks, 1984) se ha producido una restitución gráfica de los dibujos correspondientes al primer proyecto de esta obra, los cuales fueron entregados por el arquitecto el 7 de julio de 1961. La restitución se inició con la traducción de las dimensiones espaciales en dos dimensiones, tanto en planta y corte como en alzado, para llegar a una digitalización en formato DWG. Esta base digital sirvió para crear un modelo en tres dimensiones y formato STL. De tal modo, se obtiene una visión más completa y precisa de la iglesia y del conjunto del proyecto. Los resultados del proceso son las vistas que se presentan a continuación.

EG FIR NI

Vista exterior
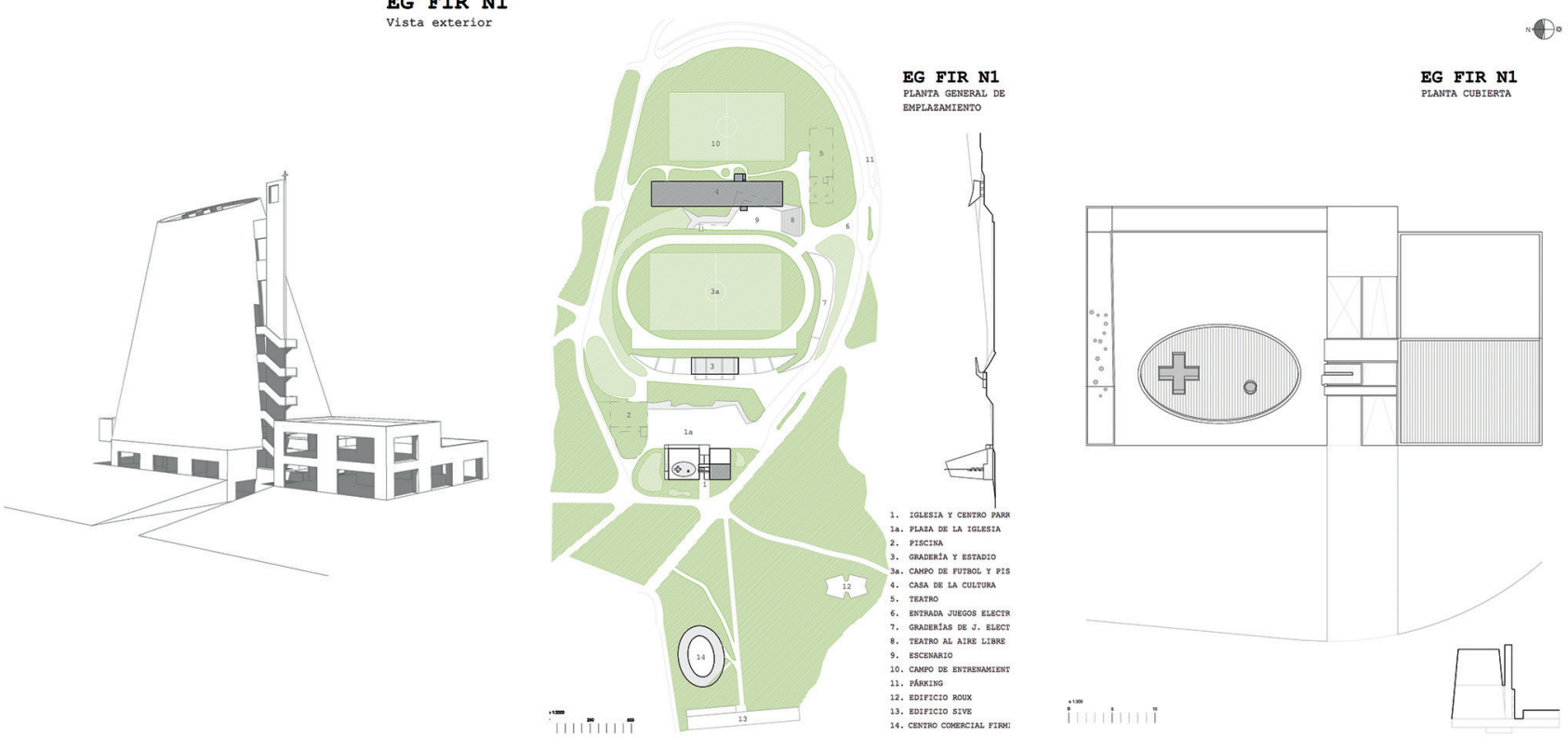

Figura 40. Vista exterior.

Figura 41. Planta general de emplazamiento.

Figura 42. Planta de cubierta Fuente: autores. 

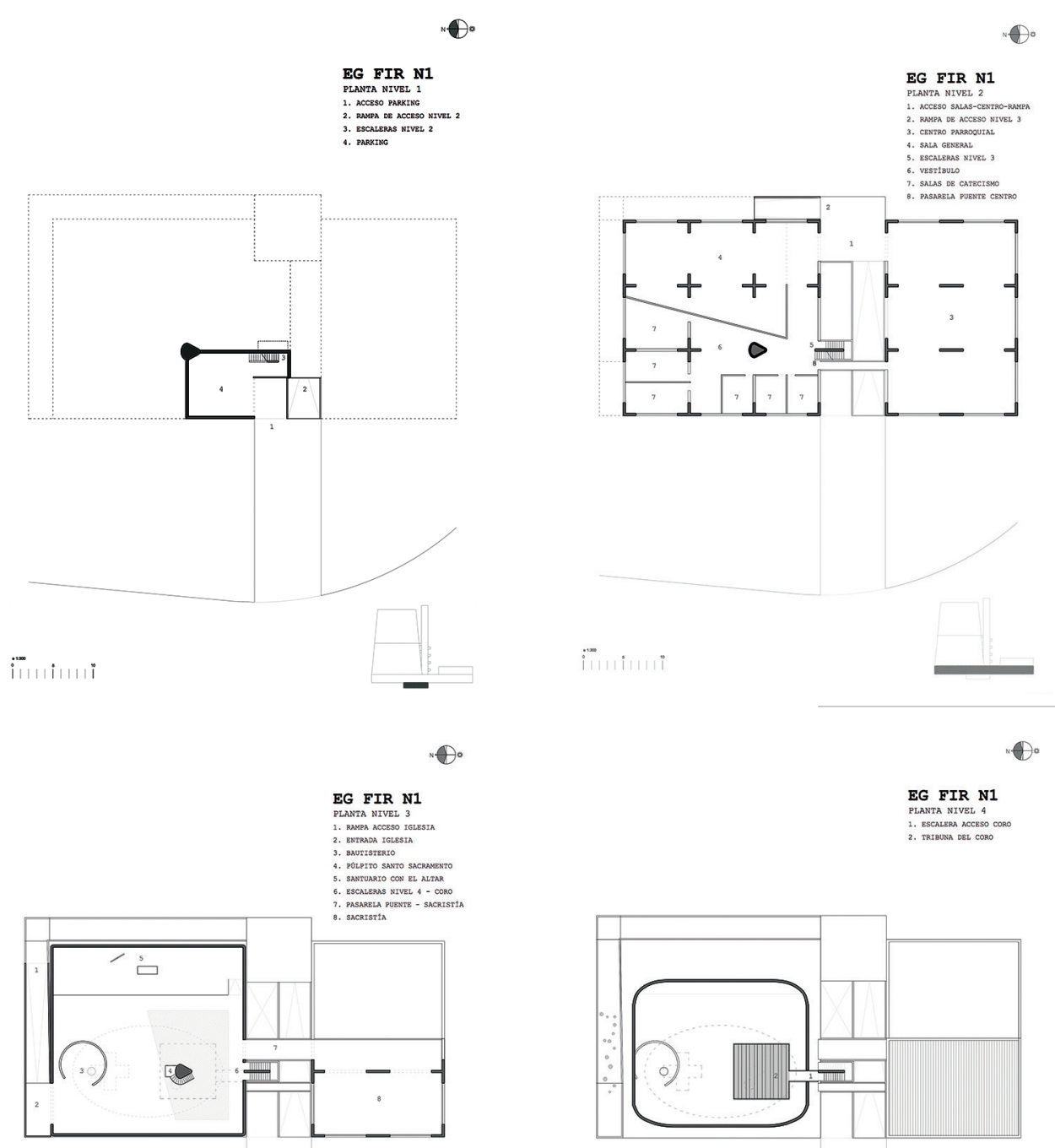

60

Figura 43. Planta de nivel 1. Figura 44. Planta de nivel 2. Figura 45. Planta de nivel 3. Figura 46. Planta de nivel 4. Fuente: autores. 

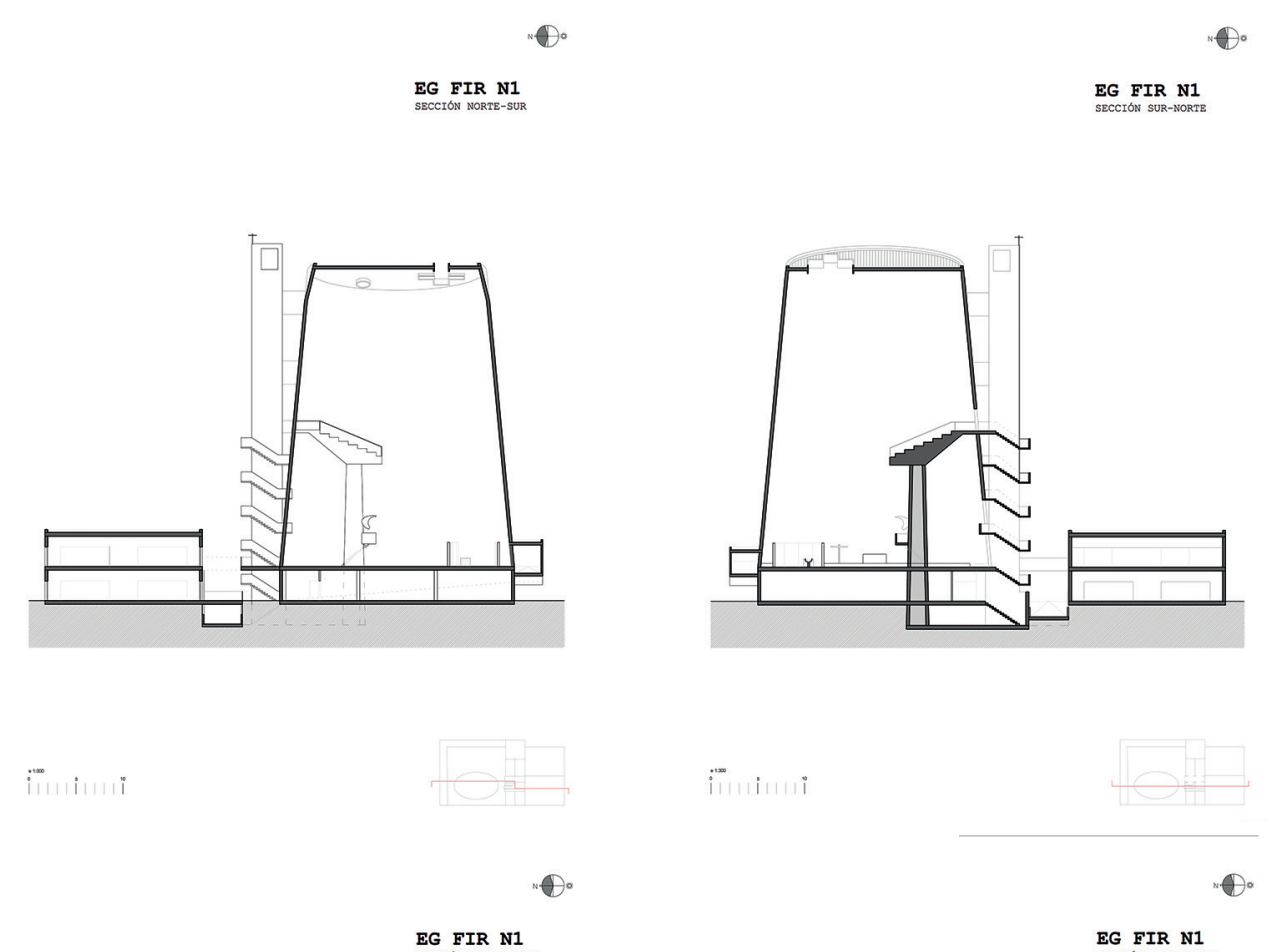

$\underset{\text { SECCIÓN OESTE-BSTE }}{\text { EG FIR N1 }}$

EG FIR N1
SECCTON ESTE-OESTE
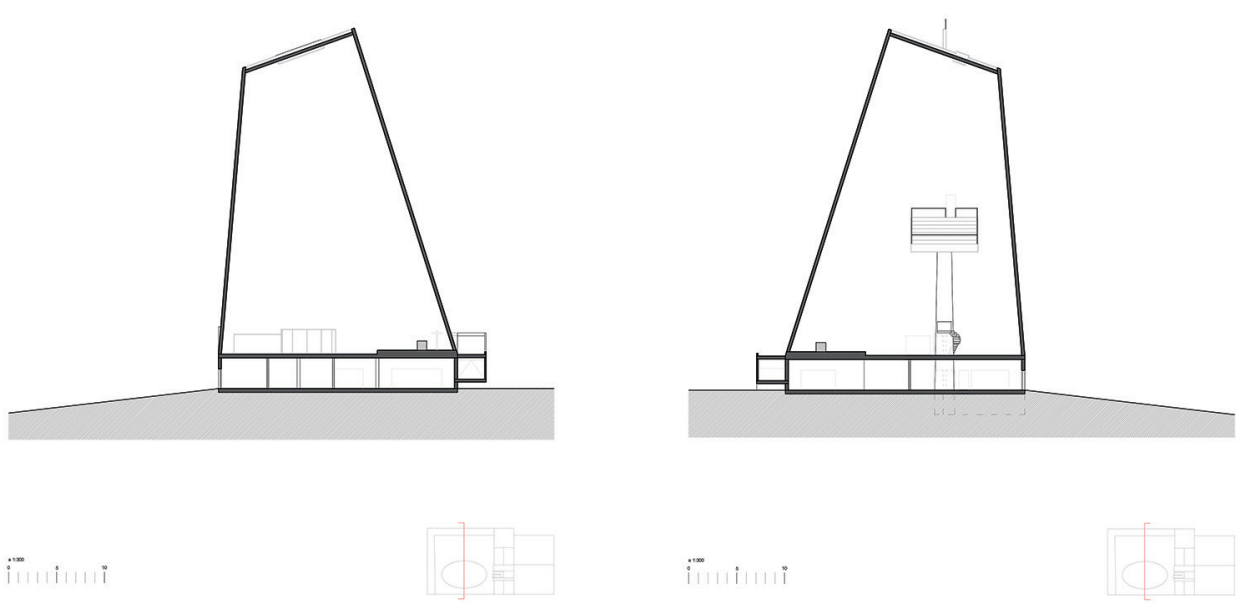

苞

61

Figura 47. Corte norte-sur.

Figura 48. Corte sur-norte.

Figura 49. Corte oeste-este .

Figura 50. Corte este-oeste.

Fuente: autores. 


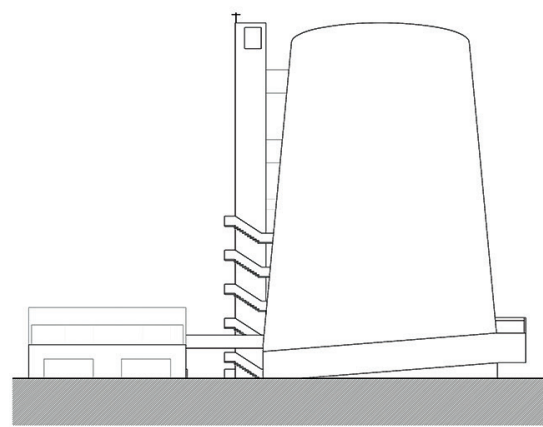

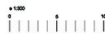

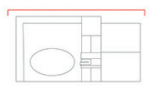

EG FIR N1

62
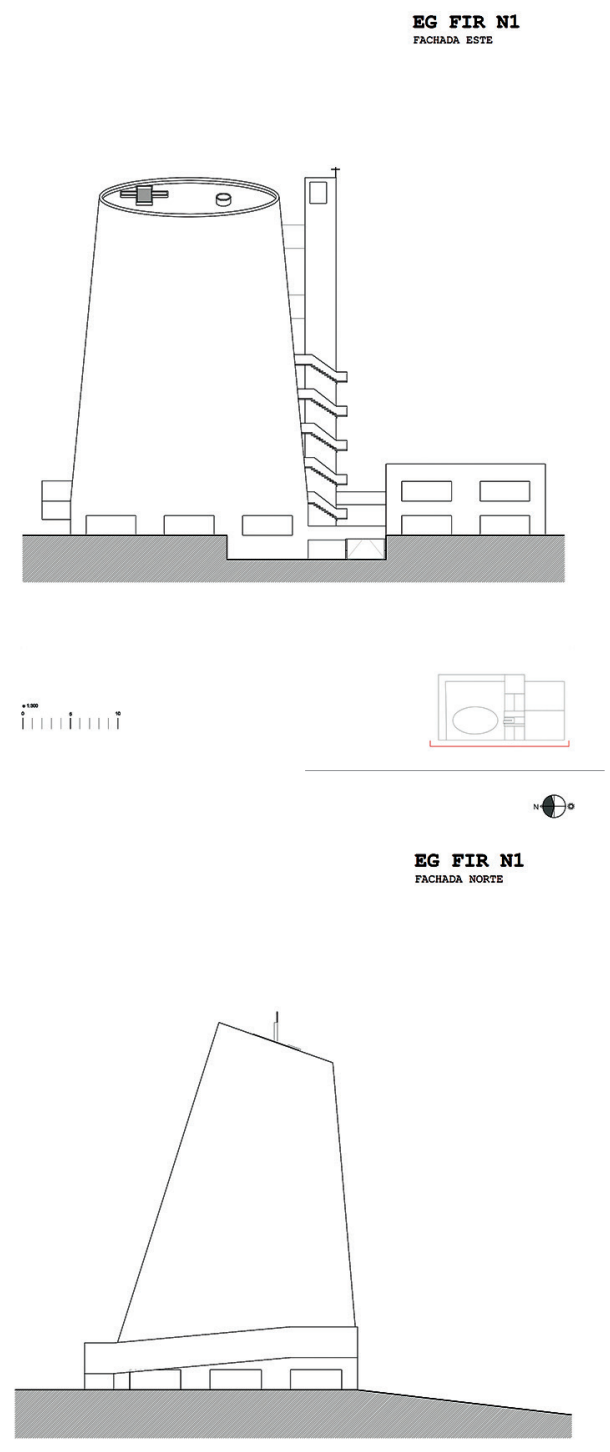

iं111illi

Figura 51. Fachada oeste. Figura 52. Fachada este. Figura 53. Fachada sur. Figura 54. Fachada norte.

Fuente: autores . 

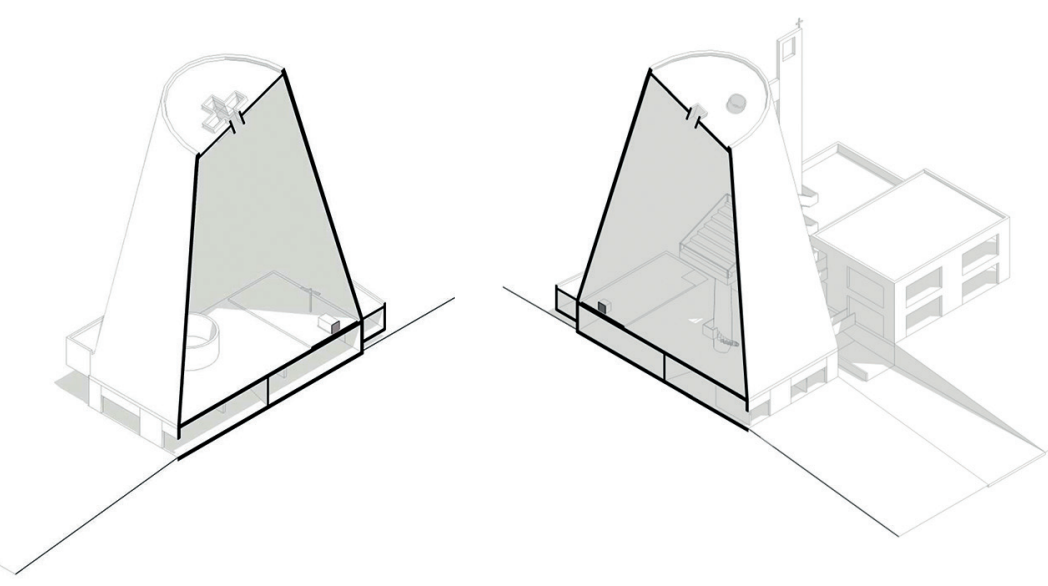

Figura 55. Isometría 1.

Figura 56. Isometría 2.

Fuente: autores .

\section{CONCLUSIONES}

En el primer proyecto se destacan elementos como la planta baja, implícitamente ligada a las condiciones del terreno. Esto afectó la implantación de la iglesia y determinó la necesidad de excavar, explanar y adaptar el terreno a las necesidades del programa, situación recurrente en las siguientes etapas. Por su parte, la rampa, el campanario y el coro materializan la circulación en forma de espiral. La rampa se desarrolla en torno al volumen vertical del edificio, en tanto la disposición elíptica 
de las escaleras se proyecta alrededor del campanario para configurar esa forma de circulación como una característica principal. La estructura vertical del campanario se complementa con la estructura vertical que soporta la tribuna del coro (figura 57), elemento que marca la direccionalidad y la espacialidad acústica del interior.
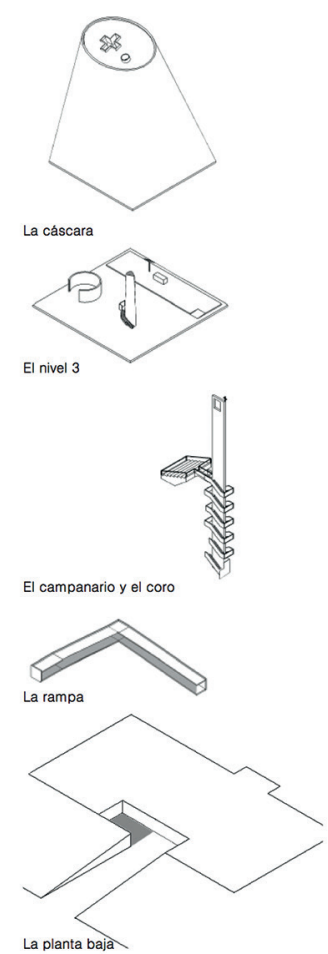

El nivel 3, determinado por la superficie del santuario y la asamblea, constituye la planta noble de la iglesia, la cual es soportada por una estructura reticular de murospantalla que permite la liberación del espacio y favorece la distribución. El binomio conformado por estos muros y el forjado reticular es una característica constructiva de Le Corbusier. Por su parte, el tablero y las columnas, elementos empleados en otros proyectos, son esenciales para configurar el suelo artificial (Monteys, 1996). El cerramiento y la cubierta del nivel se logran mediante la estructura laminar de la cáscara y el plano inclinado en forma de ovoide, elementos calados en diferentes puntos que permiten la entradas de luz de modos distintos (cenital [óculos], frontal [rosetón] y lateral [tragaluces]), para componer una gran caja de luz resonante. 


\section{REFERENCIAS BIBLIOGRÁFICAS}

Boesiger, W. (Ed). (1985). Le Corbusier: Euvre Complète 1957-1965, Volume 7. (10ª ed). Zurich: Les éditions d'architecture, Artémis.

Brooks, H. A. (Ed.). (1984). The Le Corbusier Archive: Carpenter Center, Unité d'Habitation, Firminy and other buildings and projects, 1961-1963. Paris: Fondation Le Corbusier.

Cocagnac, A. M. (1964). Un projet d'église paroissiale de Le Corbusier. L'Art Sacré, (3-4), 2-24.

Chaverra, M. (2010). Convenio de contratación para el proyecto de la Iglesia Saint-Pierre de Firminy-Vert. Revista de Arquitectura de la Universidad de los Andes, (7), 122-135.

Frampton, K. (2000). Le Corbusier. Madrid: Akal.

Franmpton, K. \& Kolbolwski, S. (eds). (1981). Le Corbusier's Firminy Church. The Institute for Architecture and Urban Studies by Rizzoli International Publications, Inc. (IAUS/Rizzoli). New York.

Franclieu, F. (Ed.). (1982). Le Corbusier Carnets, Volume 4, 1957-1964. París: Herscher/Dessain et Tolra.

Gelineau, J. (1960). Pour les églises de notre temps. L'Art Sacré. Le lieu de la célébration, (1-2), 19-29.

Gresleri, G. (1965). Chiesa \& Quartiere. Quaderni internazionali di architectura arte e urbanistica, (34).

Le Corbusier (1955). Le poème de l'angle droit. Paris: Tériade Éditeur.

Monteys, X. (1996). La gran máquina, La ciudad de Le Corbusier. Ediciones Serbal, Demarcación de Barcelona del Colegio de Arquitectos de Cataluña.

Pablo VI. (1963). Concilio Ecuménico Vaticano II. Constitución Sacrosanctum Concilium. Vaticano, p.4 